\section{Abstract}

\title{
Experimental demonstration of a mode shape-based scour monitoring method for multi-span bridges with shallow foundations
}

\author{
Abdollah Malekjafarian, Ph.D. ${ }^{1}$, Chul-Woo Kim, Ph.D. ${ }^{2}$, Eugene J. OBrien, Ph.D. ${ }^{3}$, \\ Luke J. Prendergast, Ph.D. ${ }^{4}$, Paul C. Fitzgerald, Ph.D. ${ }^{5 *}$, Syunsuke Nakajima ${ }^{6}$
}

This paper experimentally investigates a vibration-based scour monitoring approach applicable to bridges with multiple simply supported spans on shallow foundations. A monitoring strategy based on the relative changes in pier mode shape amplitudes due to scour is postulated. The first global mode shape of a bridge structure with multiple spans is extracted from acceleration measurements using an output-only approach, Frequency Domain Decomposition (FDD). The relative changes of the pier mode shape amplitudes under scour are then tracked. Here, each pier mode shape value is compared with the mean values of the remaining piers in a process that creates a Mean-Normalised Mode Shape (MNMS). The approach is demonstrated on a scaled model of a bridge with four spans, supported on sprung foundations, where scour is simulated by the replacement of springs with springs of lower stiffness corresponding to a reduction in foundation stiffness. It is shown that at a given 'scoured' pier, significant increases in the MNMS value occur, suggesting that the location of the scour can be identified. The magnitude of the MNMS at a given pier also increases with an increase in stiffness loss due to scour. In practice, the approach would work best by carrying out a visual inspection of the

1 School of Civil Engineering, University College Dublin, Dublin, Ireland. Email abdollah.malekjafarian@ucd.ie

${ }^{2}$ Department of Civil and Earth Resources Engineering, Kyoto University, Kyoto 615-8540, Japan. Email kim.chulwoo.5u@kyoto-u.ac.jp

3 School of Civil Engineering, University College Dublin, Dublin, Ireland. Email eugene.obrien@ucd.ie

${ }^{4}$ Department of Civil Engineering, Faculty of Engineering, University of Nottingham, Nottingham, NG7 2RD, United Kingdom. Email luke.prendergast@nottingham.ac.uk

5 School of Civil Engineering, University College Dublin, Dublin, Ireland. Email paul.fitzgerald.3@ucdconnect.ie

${ }^{6}$ Department of Civil and Earth Resources Engineering, Kyoto University, Kyoto 615-8540, Japan. Email nakajima.syunsuke.35x@st.kyoto-u.ac.jp 
21 bridge to establish the initial health condition at the time of sensor installation. After this initial process, the bridge can be monitored remotely for scour on an ongoing basis.

23 Keywords: Bridge scour; accelerations; mode shape; damage detection; SHM; vibrations

\section{Introduction}

Scour erosion, where soil is removed from around bridge foundations by the action of flowing water (Hamill, 1999), remains a significant hazard to bridges worldwide (Wardhana and Hadipriono, 2003, Maddison, 2012, Prendergast et al., 2018). There are three main forms of scour, general, contraction and local. General scour occurs naturally in river channels and includes the aggradation and degradation of the river bed that may occur as a result of changes in the hydraulic parameters governing flow such as changes in the flow rate or changes in the quantity of sediment in the channel (Forde et al., 1999). Contraction scour occurs due to changes in the cross-sectional (flow) area of a river due to the presence of obstructions such as piers or abutments. Local scour occurs in the direct vicinity of a bridge foundation where downward flow is induced at the upstream end of bridge piers, leading to local erosion (Forde et al., 1999).

In its simplest form, scour leads to a lowering of the soil elevation relative to foundation elements of a bridge, which can increase the vulnerability to failure. Perhaps a more significant issue occurs for bridges founded on shallow pad foundations, where scour can undermine the pad, decreasing the soil-structure contact area. This leads to increased stress on the remaining soil, increasing soil strains and ultimately reducing the shear stiffness of the soil beneath the foundation system (Oztoprak and Bolton, 2013). This type of scour mechanism is particularly dangerous because many bridges have unknown foundation depths, meaning it is difficult for bridge owners/operators to truly understand scour risk (Briaud et al., 2012). 
44 The reduction in foundation stiffness as a result of scour can lead to excessive settlements, which pose issues to bridges and can affect their load-carrying capacity. In terms of load-rating of structures to identify carrying capacity, recent efforts have sought to include foundation settlements into assessment frameworks (Davis et al., 2018).

It is widely recognised that scour reduces the stiffness of foundations, which has given rise to the area of vibration-based scour detection (Briaud et al., 2011, Foti and Sabia, 2010, Prendergast et al., 2013, Chen et al., 2014, Klinga and Alipour, 2015, Prendergast et al., 2016a, Xiong et al., 2018b, Kong et al., 2013, Fitzgerald et al., 2019a). The idea that changes in stiffness manifest themselves as changes to modal properties is the original concept behind monitoring dynamic properties for structural damage detection (Sohn et al., 2003). Many researchers have investigated approaches to scour detection based on measuring changes in various dynamic properties using sensors installed on the superstructure, or on passing vehicles (Fitzgerald et al., 2019b). These studies include both numerical and experimental investigations, and the majority of studies to date have focussed on bridges with deep foundations (piles). For a comprehensive overview of approaches based on changes in natural frequencies, interested readers are referred to Bao and Liu (2017).

Using numerical modelling, Prendergast et al. (2016a, 2016b) investigate how scour around the central pier of a two-span integral bridge influences the first natural frequency of the structure and study the ability to use changes in this frequency to detect scour. The influence of parameters such as vehicle speed and mass, road surface roughness and sensor 'noise', on the resulting lateral pier vibrations are studied to ascertain how robust the approach is for scour detection. They conclude that monitoring frequency changes shows potential to detect scour erosion. The approach is extended in Prendergast et al. (2017) to detecting the location of scour on a two-span integral bridge, i.e. which pier or abutment is scoured, by analysing multiple frequencies from the bridge with a focus on local element frequencies. Kong and Cai (2016) 
numerically investigate the dynamic response of a continuous four-span bridge under wave loads and demonstrate that scour has a significant effect on the lower frequencies of a bridge pile. Furthermore, it is shown how scour affects the complete bridge-vehicle-wave system, meaning that the response of the bridge deck or even a passing vehicle can also be used to monitor scour. Ju (2013) studies how the natural frequency of a bridge varied due to scour using numerical modelling. It is shown how water-added mass surrounding the foundations influences the frequency values and it is concluded that its presence lowers the frequency. However, accounting for water-added mass is difficult and it is recommended that it can be ignored in bridge frequency analyses. Chen et al. (2014) present a scour monitoring approach using velocity sensors and a finite-element model of a cable-stayed bridge. Combining sensor measurements with FE updating enables scour of the pier to be quantified. Klinga and Alipour (2015) perform numerical analyses on the performance of various bridge elements under extreme scour and conclude that scour reduces lateral stiffness and lowers the natural frequency. Xiong et al. (2018a) propose a scour indicator based on the bridge flexibility matrix, which is sensitive to scour-induced changes on the frequencies and mode shapes of the structure. Bao et al. (2017) perform numerical and experimental studies to investigate three particular issues with frequency-based scour detection, namely (i) the physical meaning of the predominant natural frequency (PNF), (ii) the optimal location for installed sensors, and (iii) the influence of scour hole shape. By comparing a modal PNF to one obtained from dynamic testing, separation of bridge (structural) frequencies and soil (or computational domain) frequencies is possible. In terms of optimal sensor location, they suggest locating sensors at a point near maximum modal amplitude. For the structure considered in their paper, this is the top of the pier (free end). Furthermore, they propose a new criterion to define scour depths in asymmetrical scour situations to ensure a smooth variation of PNF with scour. 
93 Several authors have trialled other types of (non-frequency) vibration-based scour detection methods on both laboratory-scale and full-scale bridges. Foti and Sabia (2010) present a study on a full-scale five span bridge where one of the piers experienced historical scour issues. By monitoring the asymmetric dynamic behaviour of the pier (due to variations in upstream and downstream scour) using the covariance of accelerations measured by an array of sensors along the foundation, they conclude that scour presence is detectable (but the extent is not quantifiable). Briaud et al. (2011) undertook experimental testing on a scaled-model bridge and investigated the performance of a range of approaches at detecting scour. One particular approach was to analyse the root-mean-square of acceleration signals measured in various directions and to use this as an indicator of scour occurrence. The ratio of RMS values showed sensitivity to scour development (Prendergast and Gavin, 2014).

The use of mode shapes to detect scour is a relatively recent development. However, mode shapes have been used in other damage detection fields to detect general forms of structural damage (cracks etc.). Damage detection methods based on changes in mode shapes are an alternative to natural frequency-based approaches, and can be advantageous in detecting local damage, and are not as prone to issues such as changes in temperature (Sohn, 2006). Structural damage detection using mode shapes generally consists of either comparing two modes from different health states of the structure, extracting features of the mode shape (e.g. curvature) that are sensitive to damage, or applying signal processing techniques to mode shape data (Fan and Qiao, 2011). Two common methods to compare shapes are Modal Assurance Criterion (MAC) and Coordinate Modal Assurance Criterion (COMAC) (Allemang and Brown, 1982, Dos Santos et al., 2000). MAC is a measure of the correlation between two modes with a value of unity representing a perfect match and a value of zero representing no match between the two modes. Hence, a reduction in MAC value may indicate the presence of damage. Salawu and Williams (1995) test MAC on mode shapes obtained from a concrete bridge before and 
118 after repair and find that the MAC values change significantly in comparison to the measured

119 frequency changes. COMAC is a pointwise comparison of two mode shapes, with a low

120 COMAC value indicating possible damage at that point. Frýba and Pirner (2001) use COMAC

121 in the repair of a segmentally constructed pre-stressed concrete bridge and show that the

122 COMAC analysis of a repaired segment was similar to that of an undamaged segment.

123 Pandey et al. (1991) show, using an analytical model, that the mode shape curvature (i.e. the second derivative of the mode shape) can detect damage in both a simply supported beam and a cantilever beam. Wahab and De Roeck (1999) use a mode shape curvature-based method on the Z24 bridge in Switzerland and develop an indicator based on the difference in curvatures before and after damage. Other authors have shown, however, that mode shape curvatures are poor for detecting smaller amounts of damage (Ratcliffe, 2000). More detailed reviews of other approaches using mode shapes are depicted in (Carden and Fanning, 2004, Fan and Qiao, 2011, Moughty and Casas, 2017, OBrien and Malekjafarian, 2016, Malekjafarian and OBrien, 2017,

131 Kong et al., 2017).

132 Some previous studies have used mode-shape based approaches to detect and monitor scour erosion. Elsaid and Seracino (2014) investigate the influence of scour on a scaled model of a coastal bridge. Scour is modelled as an increase in the effective length of bridge piles extending

135 from the deck. Mode shape curvature, flexibility-based deflection and flexibility-based 136 curvature are assessed to ascertain their performance at scour monitoring. The study concludes that horizontally-displaced mode shapes show sensitivity to the modelled scour. Moreover, the change in the mode shape curvature, flexibility-based deflections and curvatures showed promise in identifying the existence, location and possibly the extent of scour. Xiong et al.

140 (2018b) investigate four scour indicators for a scoured cable-stayed bridge, namely frequency 141 change ratio, MAC, modal curvature and flexibility-based deflection. Flexibility-based 
143 et al. (2019) present a scour identification approach based on measuring the ambient vibration

144 of the superstructure of a cable-stayed bridge. By analysing the change in the mode shapes at

145 two different times, qualitative scour identification is possible. The authors furthered the

146 procedure to enable quantitative scour identification using a companion FE model of the

147 system, whose soil stiffness is updated to match the real system.

148 The majority of previous works on vibration-based scour monitoring have focussed on changes

149 in natural frequencies to detect scour presence. Approaches using mode shapes have generally

150 focussed on direct comparison of pre- and post-scour modes using MAC-type analyses or have

151 used modal curvature and flexibility-based deflection. The majority of these studies have been

152 applied to cable-stay bridges or bridges with piled foundations. The contribution of the present

153 work relates to the use of information from the mode shape as identified from output-only

154 modal identification to detect local reductions in stiffness resulting from scour-related stiffness

155 losses. The approach developed is applicable to vertical stiffness loss experienced at shallow

156 foundations, since a majority of previous works have focussed on identifying changes in lateral

157 stiffness as would be expected at deeper foundations. Furthermore, the approach is

158 demonstrated in this paper using scaled experimental testing. The first global mode shape of

159 an experimentally scaled bridge with multiple spans is extracted using Frequency Domain

160 Decomposition (FDD) (Brincker et al., 2001). Accelerations from the bridge midspans and

161 piers are used as the input to the FDD algorithm, arising due to a model vehicle traversing the

162 structure.

163 A novel scour indicator is proposed whereby the mode shape amplitude at one pier is compared

164 to the mean of the mode shape amplitudes at the remaining piers in a process that creates a

165 Mean-Normalised Mode Shape (MNMS). It is shown that at the scoured pier, the MNMS value

166 increases due to a loss of stiffness as a result of scour. Moreover, the magnitude of the MNMS

167 at a scoured pier increases with further decreases in stiffness. The approach is also capable of 
detecting which pier is scoured by considering the nature of the changes in the MNMS. The

MNMS approach is an improvement on using the mode shape of the system alone, as it is more

171 one mode shape is required, namely the damaged mode shape, to derive the required

172 information. This means that a reference (undamaged) mode shape is not required, as would

173 be the case when comparing modes using MAC. The method only requires sensors located at

174 piers so does not suffer from the requirement of many sensors, as would be needed for accurate

175 estimates of modal curvature, for example. The method may be suited to output-only scour

176 identification for multi-span bridges founded on shallow pad foundations, which typically have

177 not received much attention in the literature.

178 Scour monitoring approach based on pier mode shape values

179 Numerical Model

180

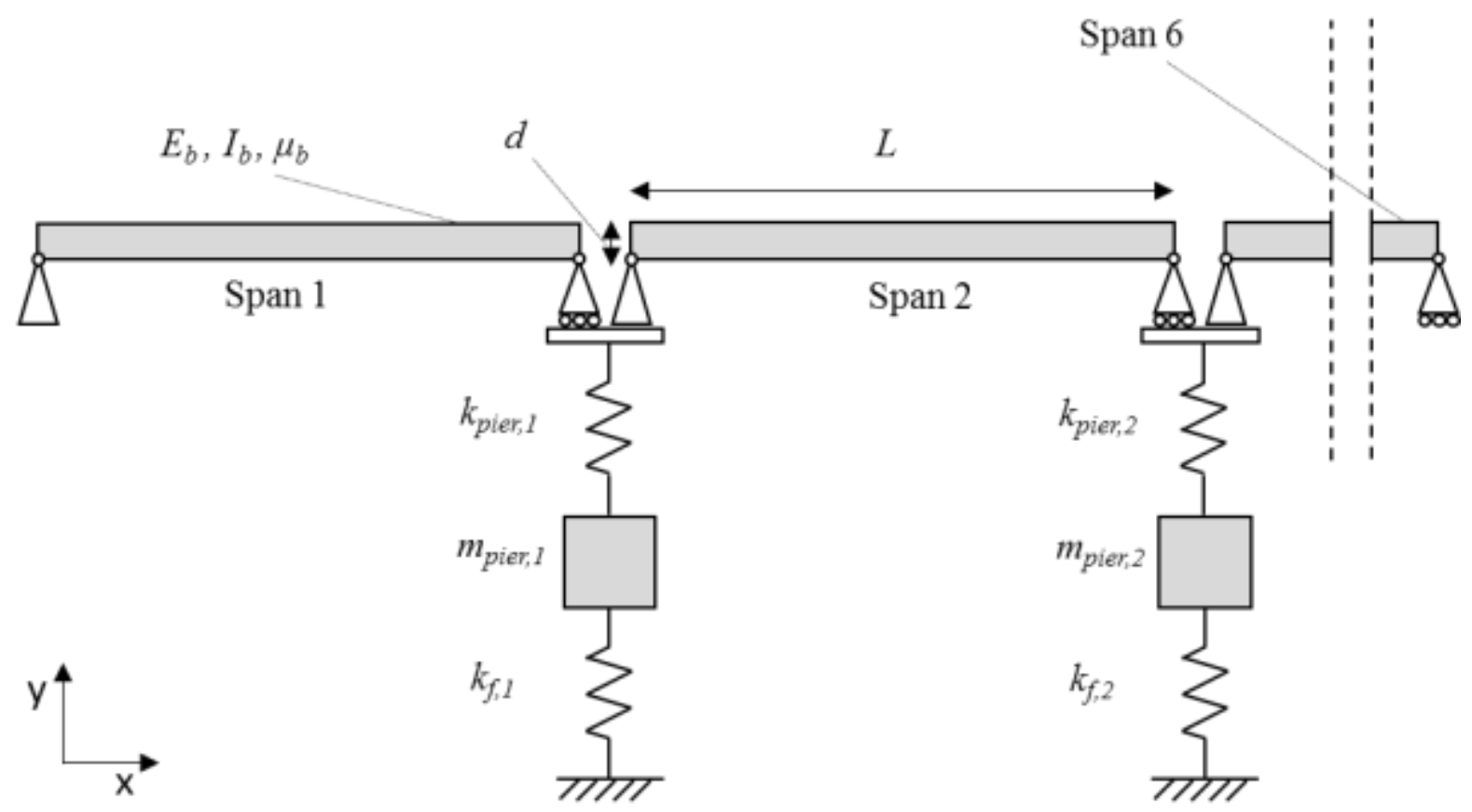

181

Fig. 1: Numerical model schematic 
182 A numerical model is used to introduce the scour detection procedure and a schematic of this

183 is shown in Fig. 1. It represents a bridge with pinned connections (internal hinges) between

184 each of six spans. Each pier is assumed to rest on a shallow pad foundation with underlying

185 soil stiffness. Each span is modelled as a simply supported Euler-Bernoulli beam, the mass and

186 stiffness matrices for which are available in (Kwon and Bang, 2000). The beginning and end

187 of the bridge are assumed to rest on undeformable abutments, which are modelled as pinned,

188 and roller supports, respectively. Hence, there are five internal piers. Twenty $1 \mathrm{~m}$ long beam

189 elements are used for each span in the finite-element model. The beams are connected using

190 nodal hinges with a supporting pier at each connection, modelled as a single degree of freedom

191 (DOF) sprung-mass in the vertical direction.

192 Each pier is supported by a spring, $k_{f}$, which represents the vertical stiffness provided by a shallow pad foundation with notional length, $L$ and width, $B$ dimensions of $4 \mathrm{~m}$ and $2 \mathrm{~m}$ respectively. Using these pad dimensions, the stiffness of the spring is calculated using the approach in FEMA (2000), see Eq. (1),

$$
k_{f}=\frac{G B}{1-v}\left[1.55\left(\frac{L}{B}\right)^{0.75}+0.8\right]
$$

197 where $G$ is the operational shear modulus of the soil $\left(\mathrm{kN} \mathrm{m}^{-2}\right)$ and $v$ is the small-strain Poisson ratio. An elastic modulus, $E=(2 G(1+v))$, corresponding to a medium dense sand (Prendergast and Gavin, 2016) is assumed for the unscoured stiffness. Note, the expression in Eq.(1) is semiempirical and there exists several formulations that take this approximate form (Pais and Kausel, 1988, Mylonakis et al., 2006). Table 1 lists the main geometrical and material properties of the bridge. The second moment of area is calculated by assuming a $4 \mathrm{~m}$ wide single-track railway bridge with a rectangular cross-section and the mass and stiffness of the

204 pier is calculated by assuming pier dimensions of $7 \mathrm{~m}$ (in y-direction), $1 \mathrm{~m}$ (in x-direction) and 
$2.5 \mathrm{~m}$ (into page) with a modulus of elasticity and density of $35 \times 10^{6} \mathrm{kN} \mathrm{m}^{-2}$ and $2400 \mathrm{~kg} \mathrm{~m}^{-3}$ respectively.

Table 1: Properties of bridge used to introduce the scour identification approach

\begin{tabular}{|l|l|l|l|}
\hline Property & Symbol & Unit & Value \\
\hline Span length & $L$ & $\mathrm{~m}$ & 20 \\
\hline Beam depth & $d$ & $\mathrm{~m}$ & 1 \\
\hline Beam second moment of area & $I_{b}$ & $\mathrm{~m}^{4}$ & 0.33 \\
\hline Beam modulus of elasticity & $E_{b}$ & $\mathrm{kN} \mathrm{m}^{-2}$ & $35 \times 10^{6}$ \\
\hline Beam mass per unit length & $\mu_{b}$ & $\mathrm{~kg} \mathrm{~m}^{-1}$ & $9.60 \times 10^{3}$ \\
\hline Pier mass & $m_{\text {pier }}$ & $\mathrm{kg}^{-1}$ & $42 \times 10^{3}$ \\
\hline Pier stiffness & $k_{\text {pier }}$ & $\mathrm{kN} \mathrm{m}^{-1}$ & $12.50 \times 10^{6}$ \\
\hline $\begin{array}{l}\text { Vertical stiffness provided by shallow } \\
\text { pad foundation }\end{array}$ & $k_{f}$ & $\mathrm{kN} \mathrm{m}^{-1}$ & $344.12 \times 10^{3}$ \\
\hline
\end{tabular}

209 In this work, scour is modelled as a reduction in stiffness of a given vertical foundation spring.

210 It is worth noting that in the real case a loss of rotational stiffness could occur as a result of

211 scour which would result in rocking effects on the pad. This type of situation could arise in the

212 case of asymmetric scour affecting the foundation (Foti and Sabia, 2010). However, the present

213 study specifically focuses on vertical stiffness loss only (Eq. 1). The basis for scour-related

214 stiffness loss lies in the stress and strain dependency of soil stiffness, as discussed herein. The

215 shear modulus of soil $(G)$ typically increases nonlinearly with mean effective stress. The

216 magnitude of this shear modulus at a given depth is a function of the amount of overburden

217 pressure at that location. Scour leads to a local reduction in soil elevation relative to a

218 foundation, which implies the overburden pressure reduces in the vicinity of scoured

219 foundations (Zhang et al., 2017). It can therefore be assumed that scour occurrence would

220 change the operational shear modulus at formation level, although by a small amount. In extreme cases, however, scour can undermine a shallow pad (Scozzese et al., 2019). When this occurs, the contact area between the remaining soil beneath the shallow foundation and the pad is reduced, leading to increased stress on the remaining soil from the applied loads. This 
increased stress subsequently increases the strain in the soil, due to the typically nonlinear stress-strain relationship of soil. Additionally, the shear modulus of soil is strain-dependant, and typically reduces with strain (Oztoprak and Bolton, 2013, Hardin and Drnevich, 1972). In this paper, both the aforementioned mechanisms are assumed to occur leading to a reduction in the vertical stiffness of a foundation under scour. For the geometries considered in the present study, a $30 \%$ example loss in stiffness would be expected if the foundation was undermined by scour reducing the soil-foundation contact area from $8 \mathrm{~m}^{2}(4 \mathrm{~m} \times 2 \mathrm{~m})$ to $5.1 \mathrm{~m}^{2}$

$231(3 \mathrm{~m} \times 1.7 \mathrm{~m})$, with a corresponding reduction in soil shear modulus, $G$ equating to $10 \%$ 232 reduction from the small-strain value $G_{0}$ (Oztoprak and Bolton, 2013).

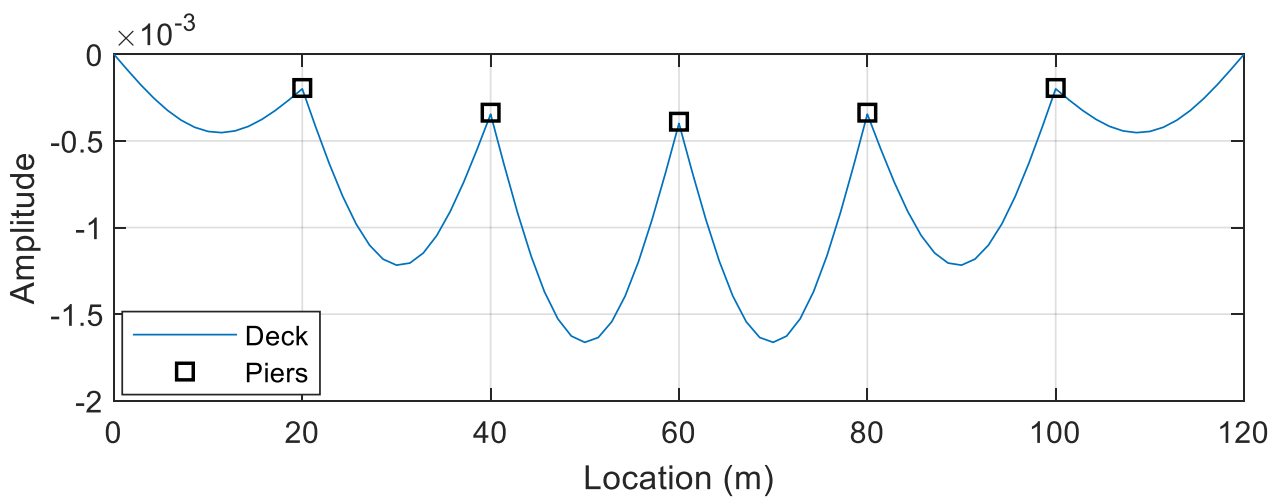

Fig. 2: First mode shape of system for healthy case $-3.70 \mathrm{~Hz}$ frequency

Fig. 2 shows the first global mode shape of the bridge corresponding to the first natural frequency of the system when there is no scour. The mode shape is derived from the system mass and stiffness matrices by solving the Eigenproblem (Clough and Penzien, 1993). As is evident, each of the bridge spans exhibit a bending shape with each of the piers exhibiting motion in the same direction for this mode. The central pier has the highest maximum mode

240 shape amplitude relative to the remaining piers. The first mode shape of the bridge will be used to develop a scour monitoring approach by investigating the sensitivity of this mode to scour at various locations. 


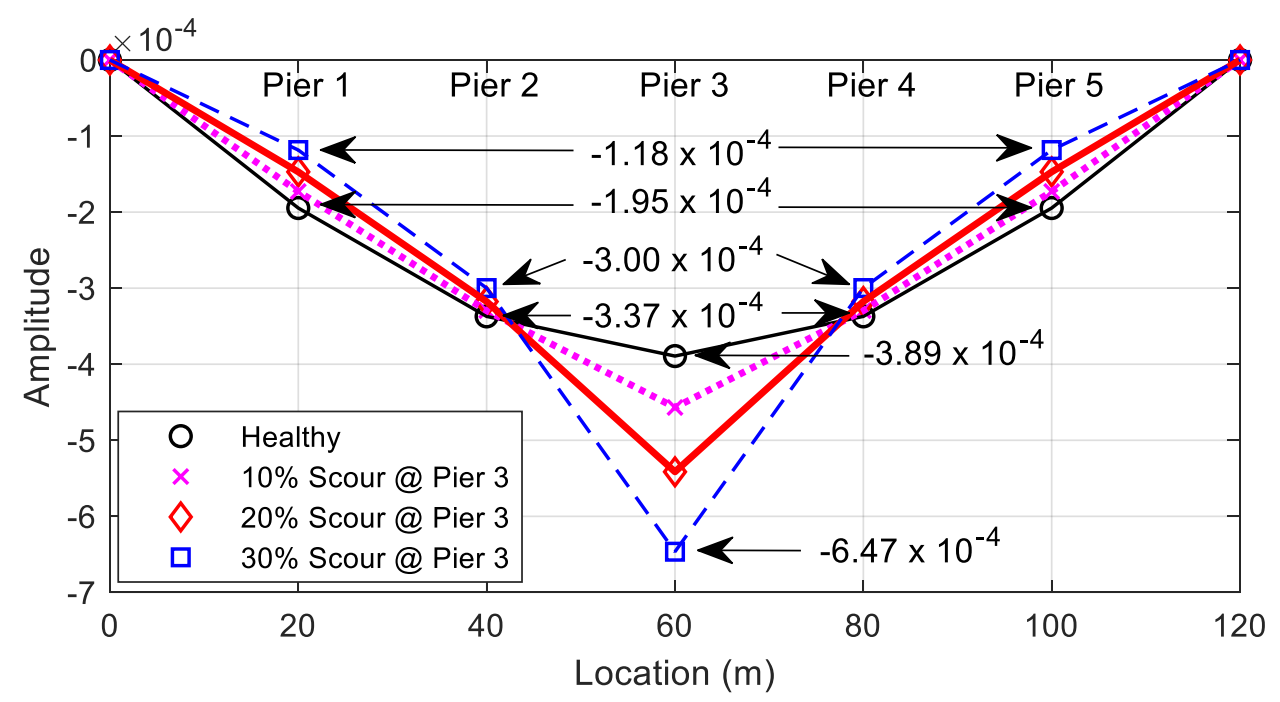

Fig. 3: First mode shape amplitude at pier locations of bridge system due to varying levels of stiffness loss as a result of scour at Pier 3 (60 m point).

247 Fig. 3 shows how the stiffness loss due to scour affects the first mode shape of the system for

248 scour at the central pier of the bridge. In this plot, the percentage scour refers to percentage stiffness loss as a result of scour, and is defined as the reduction in vertical foundation stiffness with respect to the stiffness of a foundation with zero scour. Only the mode shape values at the pier locations are shown here and the spans are simplified as straight lines. For each scenario, the modes are normalised with respect to the system mass matrix so that they can be quantitatively compared. In this work, a scour indicator based on the first mode shape amplitudes at the locations of the piers is proposed. The first mode shape is used to develop the scour indicator because for this mode, all of the piers exhibit movement in the same direction enabling a ratio-type indicator to be created. Fig. 3 shows that the largest change in the mode shape amplitude occurs at the scoured pier. It is of note that the mode shape amplitude is affected at unscoured piers also. At the scoured pier the absolute value of the modal amplitude increases with an increase in scour (reduced stiffness). At unscoured piers, the opposite effect is observed whereby the absolute value of the amplitude decreases with an increase in scour. It should be noted that the changes at the scoured pier are much greater than those at the 
unscoured piers. Based on this premise, a scour indicator referred to as the Mean Normalised

Mode Shape (MNMS) is proposed to compare the mode shape value of a given pier with those

264 at the other piers. The mean value of the modal amplitudes of the remaining piers is used as

265 the metric to compare each pier mode shape value. In mathematical form, the MNMS at any

266 pier is represented as Eq. (2).

$$
\{M N M S\}_{x}=\frac{\{M S\}_{x}}{\frac{1}{n-1} \sum_{\substack{k=1 \\ k \neq x}}^{n}\{M S\}_{k}}
$$

where $n$ is the total number of piers, which in this case is equal to five, $x$ is the pier number such that $\mathrm{x} \in\{1: n\}, M S$ is a vector of pier mode shape amplitudes and the summation term represents the sum of the pier mode shape amplitudes excluding Pier $x$.

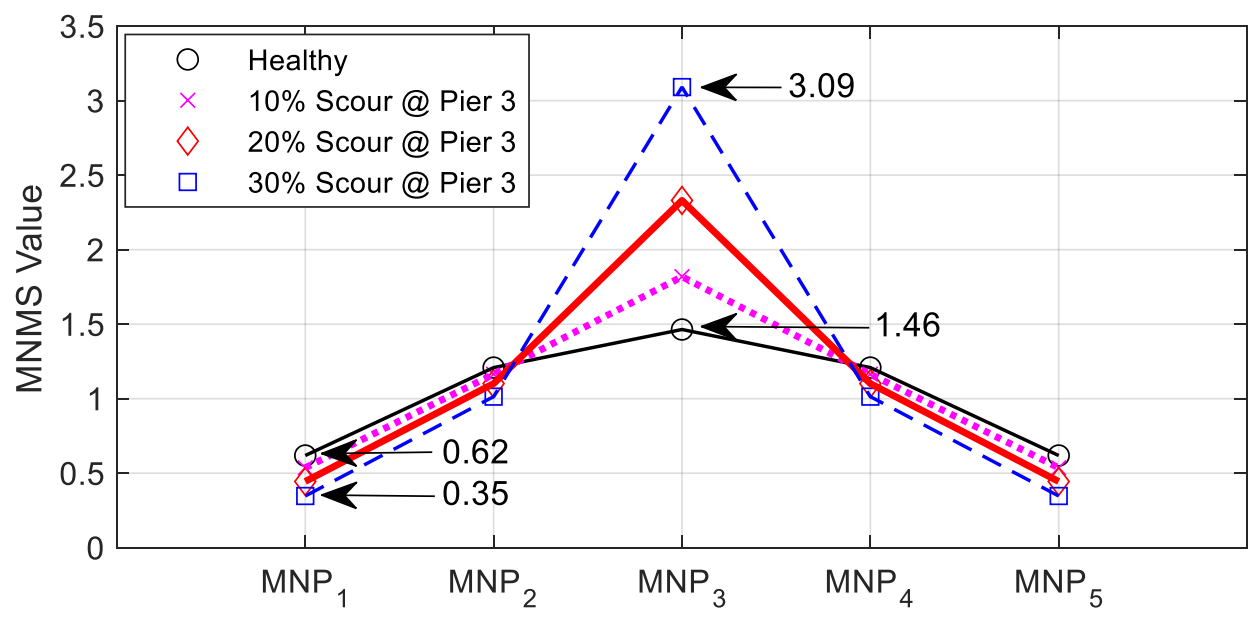
Fig. 4: MNMS values for each pier for varying levels of scour at Pier 3

273 Fig. 4 shows how the MNMS at each pier is affected by the stiffness loss due to scour at Pier

274 3. At the scoured pier (Pier 3), the MNMS increases with an increase in scour severity from 2751.46 when there is no scour affecting the bridge to 3.09 when scour corresponding to a $30 \%$ 276 decrease in Pier 3 foundation stiffness affects the structure. At other (unscoured) piers, the 
MNMS values decrease with an increase in scour severity at Pier 3. For example, the MNMS value at Pier 1 decreases from 0.62 to 0.35 where there is $30 \%$ scour at Pier 3 .

It is clear that the MNMS pattern (Fig. 4) has a strong resemblance to the mode shape values

280 themselves (Fig. 3). The main advantage of using the MNMS over direct mode shape

281 comparison lies with the fact that for mode shapes, normalisation is required to facilitate comparison. The mode shapes derived from an output-only modal method like FDD are not mass-normalised as the input forces are unknown (Khatibi et al., 2012). This means that the magnitude of the mode shape values depends on the amplitude of the input forces. For example, a passage of a heavy vehicle may generate signals with higher modal amplitudes than a lighter vehicle. The normalisation process could affect the observed changes due to scour. A common practice for depicting operational mode shapes is to normalise them with respect to their maximum value (Khatibi et al., 2012). However, normalising the mode shapes in this way could lead to a situation where the modes exhibit no change at the location of the scoured pier - which would be the case in Fig. 3. The metric defined in Eq. (2) avails of the relative changes in the mode at various points, therefore it is insensitive to changes in modal magnitude resulting from the passage of different vehicles.

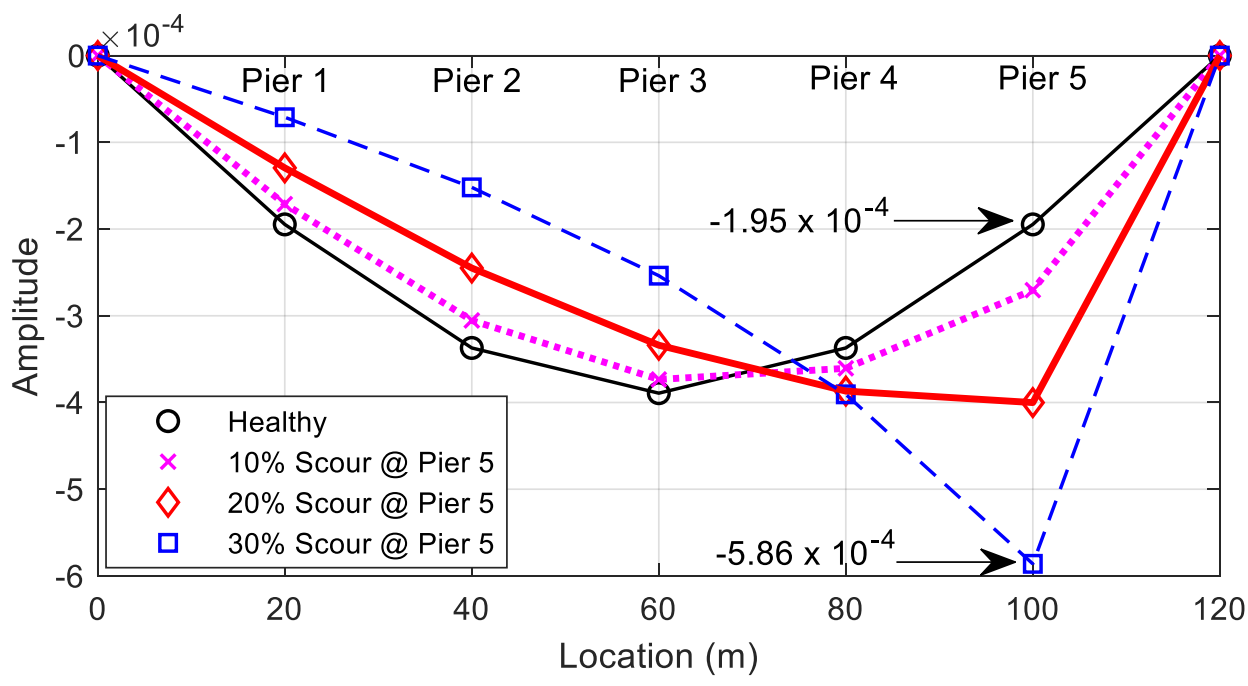

Fig. 5: First mode shape amplitude at pier locations of bridge system due to varying levels of stiffness loss as a result of scour at Pier 5 (100 m point). 


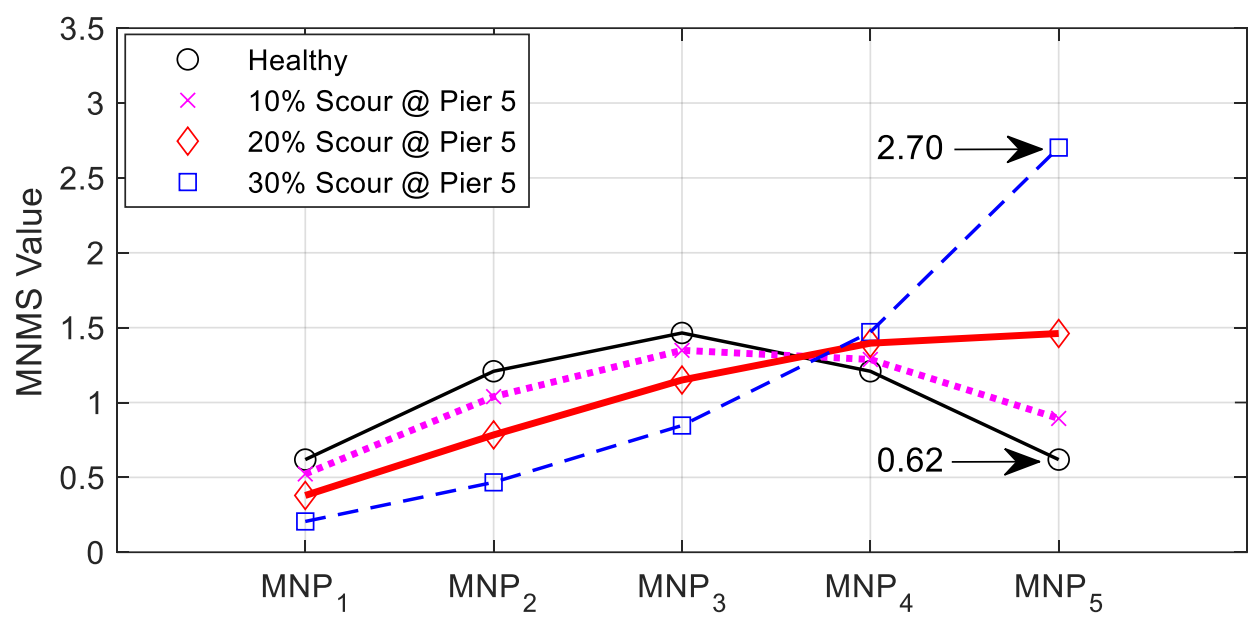

Fig. 6: MNMS values for each pier for varying levels of scour at Pier 5

298 Fig. 5 shows how increasing stiffness loss at Pier 5 influences the mode shape amplitudes at each pier. Fig. 6 shows the corresponding MNMS values at each pier. The MNMS values defined in Eq. (2) experience a greater percentage change at the scoured pier than the raw mode shape values at this location (335\% as opposed to $200 \%$ for the $30 \%$ scour case). Note also that the mode shapes in this case are mass-normalised mode shapes directly from Eigen-analyses. In the real case, they would have to be computed from time domain data, making them less reliable. Fig. 6 exhibits a broadly similar trend to that of Fig. 4 in that at the scoured pier, the MNMS value increases while at the unscoured piers it decreases. However, in this case, Pier 4 which is closest to the scoured pier also exhibits an increase in MNMS value. The mode shape itself also reflects this (see Fig. 5) as both Piers 4 and 5 show an increase in absolute mode shape value due to scour at Pier 5.

\section{Frequency Domain Decomposition (FDD)}

310 It is not possible to extract the mode shapes using an eigenvalue analysis on a real structure.

311 Instead, it is necessary to derive modal information by analysing time-domain signals measured

312 from a target structure. In this work, Frequency Domain Decomposition (FDD) (Brincker et 313 al., 2001) is used as a means to extract mode shapes from acceleration measurements. FDD is an output-only modal identification method, i.e. it enables estimation of the system dynamic 
315 parameters without prior knowledge of the input excitation. The approach is suitable for a scenario where a bridge is excited by unknown vehicle properties.

317 FDD begins with the estimation of the power spectral density (PSD) matrix, $\hat{\mathrm{G}}(j \omega)$, from the

318 various responses at discrete frequencies for $\omega=\omega_{i}$. Next, $\hat{\mathrm{G}}(j \omega)$ is decomposed at each 319 frequency by applying Singular Value Decomposition (SVD) (Brincker et al., 2001) to obtain 320 Eq. (3).

$$
\hat{G}\left(j \omega_{i}\right)=U_{i} S_{i} U_{i}^{H}
$$

where $U_{i}$ is a unitary matrix of singular vectors, $S_{i}$ is a diagonal matrix holding the singular values and $H$ denotes the complex conjugate of the matrix. Using the singular values obtained at each frequency, an SVD diagram can then be plotted. From this plot, the natural frequencies of the structure can be obtained from the dominant peaks and the corresponding singular vectors are the mode shapes.

\section{Minimum stiffness loss that can be detected by the MNMS approach under}

\section{noisy conditions}

It is of interest to assess the minimum stiffness loss that can be detected by the approach postulated in this paper. To investigate this, a time-domain analysis is conducted whereby the external excitation is by means of a simulated quarter car crossing the bridge model described previously. A quarter car (with two degrees of freedom and crossing speed of $80 \mathrm{~km} / \mathrm{h}$ ) is coupled with the bridge model to form a vehicle-bridge interaction (VBI) model (Keenahan et al., 2013, OBrien et al., 2017) and properties of the quarter car are taken from the literature (Fitzgerald et al., 2019b). Forced vibration data and 5s of free vibration pier acceleration data extracted from the VBI model is inputted to the FDD algorithm from which the mode shapes are extracted. Before they are inputted into the FDD algorithm, noise is added to the clean 
acceleration signals from the model to generate more realistic accelerations. Random noise is added to the acceleration signals using Eq. (4):

$$
\{a\}=\left\{a_{\text {calc }}\right\}+E_{p}\left\{N_{\text {noise }}\right\}\left\{a_{\max }\right\}
$$

341 where $a$ is the noisy acceleration signal, $E_{p}$ is the level of noise, $N_{\text {noise }}$ is a normally distributed vector with a standard deviation equal to one, $a_{\text {calc }}$ is the clean acceleration signal outputted from the VBI model and $a_{\max }$ is the maximum value of the signal. The level of noise is chosen

344 to be $5 \%$, which is consistent with values used in the literature (Zhu and Law, 2002, 345 Malekjafarian and OBrien, 2014). Keeping the same excitation source, the mode shape 346 extraction process is repeated 10 times, each for a healthy bridge case, and seven scour 347 scenarios ranging from a $2.5 \%$ to $17.5 \%$ stiffness loss at the central bridge pier. The MNMS is 348 calculated for each run in every scenario, enabling mean and standard deviations of MNMS 349 values to be obtained for each case. Fig. 7 shows an error bar plot (mean +/- one standard 350 deviation) for the MNMS value of the central pier. It can be seen that there are overlaps in the 351 error bars for the lower stiffness loss cases and the healthy case (0\% stiffness loss). At around $3527.5 \%$ stiffness loss, there is a clear distinction relative to the error bars of the healthy case.

353 However, the error bars for stiffness losses between $2.5 \%$ and $12.5 \%$ show an overlap with one 354 another. This suggests that a more realistic estimation for the minimum stiffness loss that can 355 be detected would be greater than $10 \%$. Here, for differences of $12.5 \%$, there are no overlaps 356 between the error bars. 


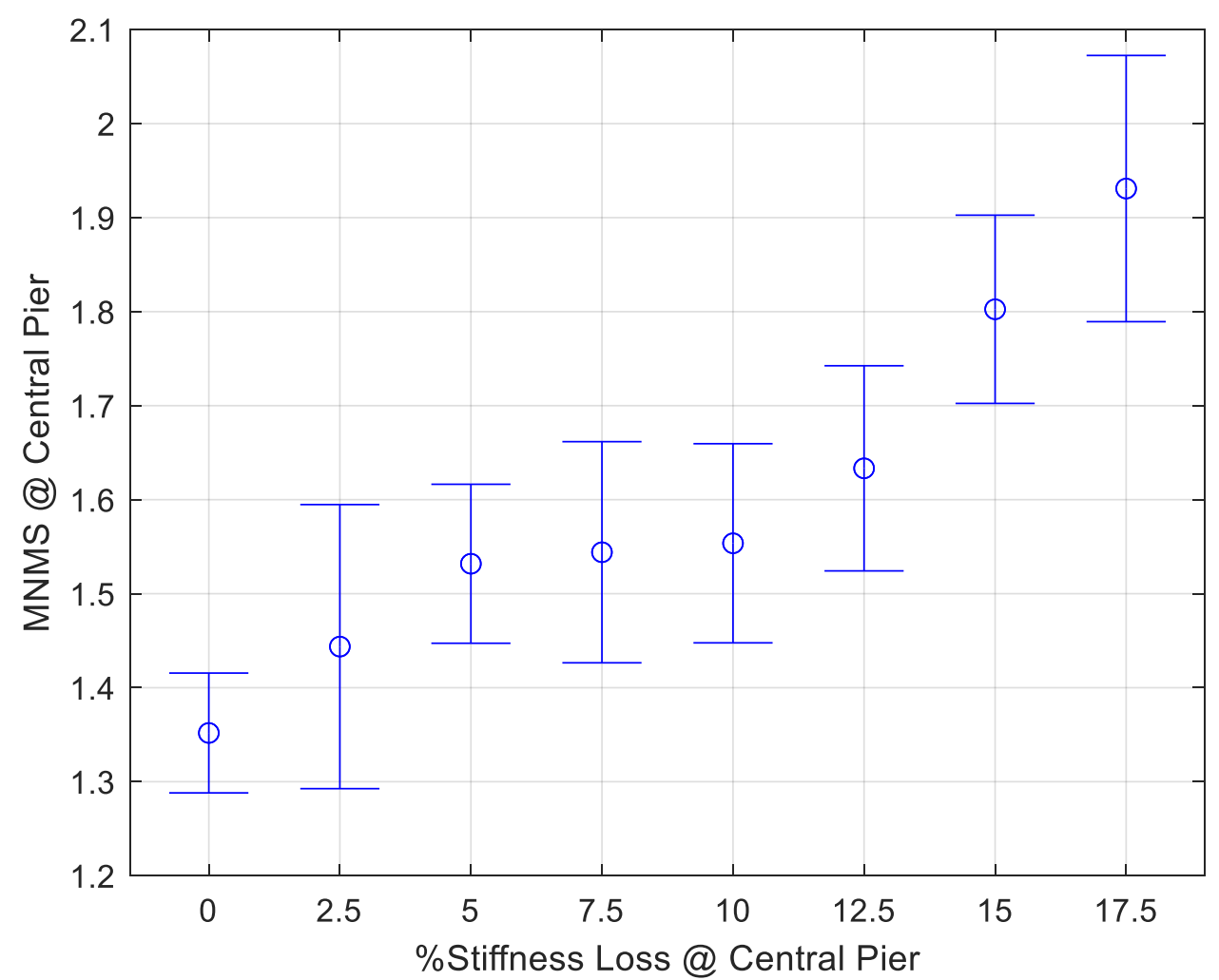

Fig. 7: Minimum scour detectable considering natural variation due to noise of MNMS

\section{Experimental Model}

360 The previous sections introduced the concept of MNMS and demonstrated it via numerical

361 modelling. In this section, a scaled model of a bridge with multiple simply supported spans has

362 been developed to experimentally validate the MNMS concept. The tests were conducted in a

363 laboratory at Kyoto University in Japan. 
364 Bridge

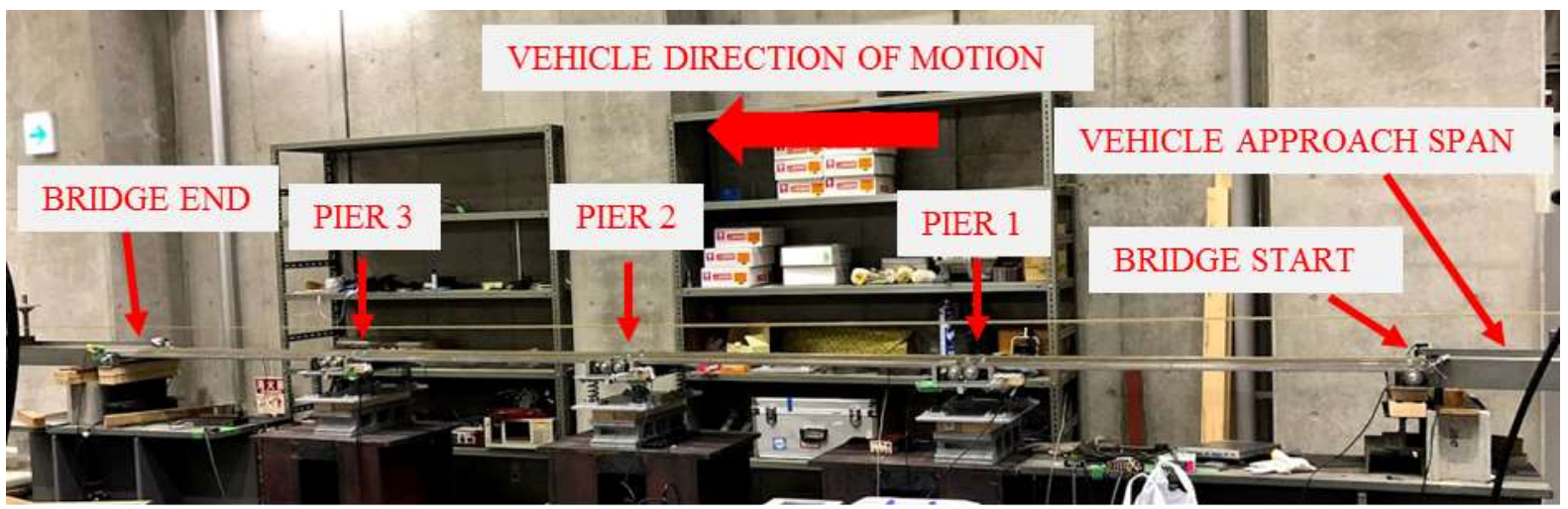

(a)

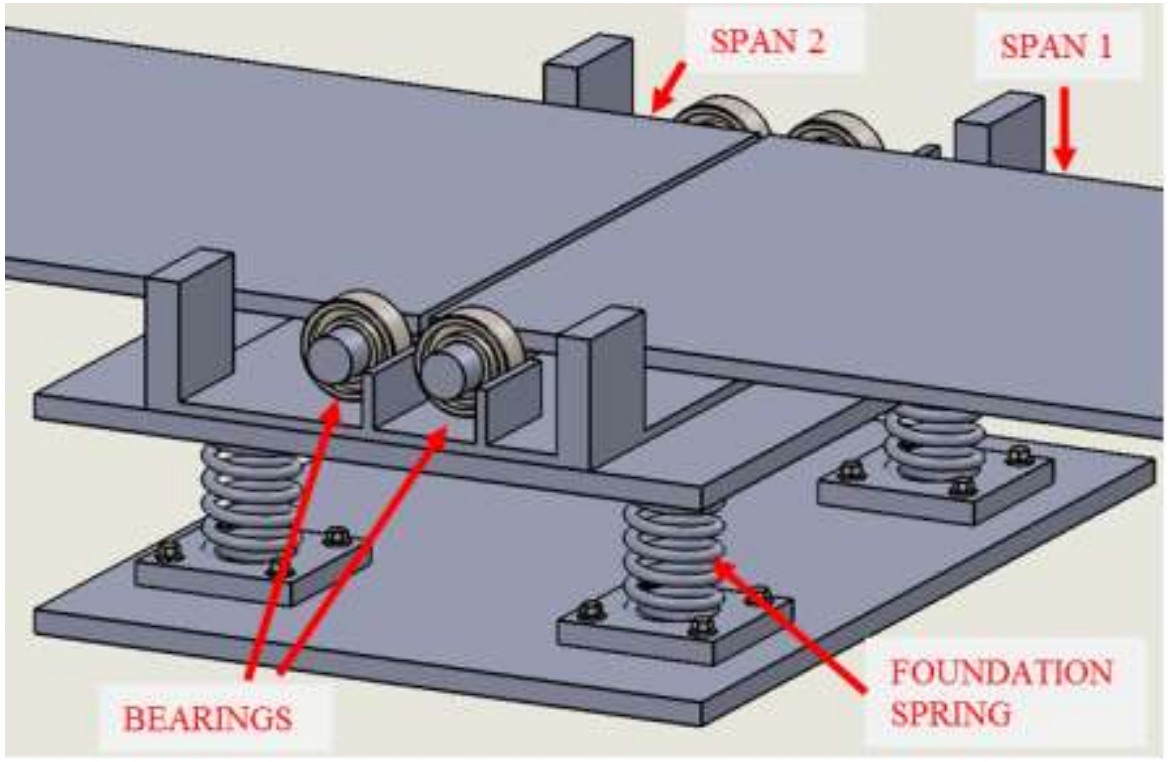

(b)

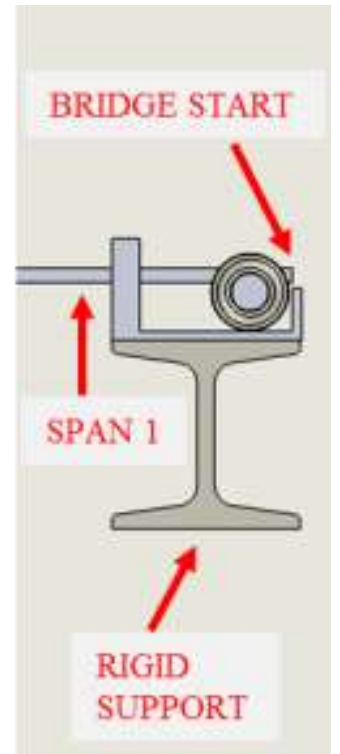

(c)
366
Fig. 8: Experimentally scaled multi-span bridge (a) full bridge (b) pier supported on four springs (in this case Pier 1) (c) rigid support at bridge extremes

The model bridge consists of four spans supported on three piers - see Fig. 8(a). The bridge was traversed by a scaled model vehicle to generate the external excitation. Each pier was founded on four springs of equal stiffness, to provide vertical stability, and bearings were used to create pin and roller supports (Fig. 8(b)). The start and end of the bridge rest on rigid supports and do not deflect (Fig. 8(c)). Table 2 provides the properties of the beam used for each bridge span. 
Table 2: Span details

\begin{tabular}{lll}
\hline Property & Unit & Value \\
\hline Span length & $\mathrm{mm}$ & 1300 \\
\hline Width & $\mathrm{mm}$ & 300 \\
\hline Beam depth & $\mathrm{mm}$ & 8.07 \\
\hline $\begin{array}{l}\text { Second moment of area } \\
\text { (rectangular cross section) }\end{array}$ & $\mathrm{m}^{4}$ & $1.31 \times 10^{-8}$ \\
\hline Modulus of elasticity & $\mathrm{N} \mathrm{m}^{-2}$ & $2.05 \times 10^{11}$ \\
\hline Density & $\mathrm{kg} \mathrm{m}^{-3}$ & 7850 \\
\hline
\end{tabular}

376

377 The stiffness of the foundation springs was determined from load-displacement testing and

378 benchmarked against geotechnical analyses assuming small-strain linear behaviour, which is

379 appropriate for bridges traversed by moving vehicles. Spring values were defined for the scaled

380 model and a scaling criterion was applied to check compliance at full-scale dimensions, as

381 described herein. The stiffness of each spring used in the experiment (for the healthy bridge

382 scenario) is $49 \mathrm{~N} \mathrm{~mm}^{-1}$. As four springs were used in parallel beneath each pier, the

383 experimental equivalent stiffness under each support, $k_{f, E X P}$, was $196 \mathrm{~N} \mathrm{~mm}^{-1}$. In order to

384 achieve compliance with an equivalent full-scale model, a scaling criterion is defined as the

385 ratio of (i) the midspan deflection of a simply supported beam with a unit static load applied

386 directly at midspan, and (ii) the deflection of the support spring when a unit static load is

387 applied directly over a pier. In the numerical model employed to introduce the procedure in the

388 previous section, the stiffness of the pier $\left(k_{\text {pier }}\right)$ is greater than the foundation stiffness $\left(k_{f}\right)$ by a

389 factor of 36 . Therefore, in this criterion the equivalent stiffness of the two in series is governed

390 by the stiffness provided by the shallow pad foundation.

391 In mathematical form, the midspan deflection of a simply supported beam due to a static unit

392 load at the centre is shown in Eq. (5)

$$
d_{\text {mid }}=\frac{L^{3}}{48 E I}
$$


where $L$ is the beam span length, $E$ is the Young's Modulus and $I$ is the beam second moment of area. The deflection at a pier, $d_{\text {pier }}$, due to a unit static load immediately overhead, is simply the reciprocal of the stiffness provided by the shallow pad foundation (i.e. $1 / k_{f}$ ). By maintaining the ratio of $d_{\text {mid }}$ to $d_{\text {pier }}$ between a full-scale numerical model and the scaled experiment, the experimental foundation stiffness can be represented as Eq. (6)

$$
k_{f, E X P}=k_{f, N U M}\left(\frac{L_{N U M}^{3} E_{E X P} I_{E X P}}{L_{E X P}^{3} E_{N U M} I_{N U M}}\right)
$$

where subscripts EXP and NUM denote the experimental and numerical full scaled model respectively.

Using the scaling criterion defined in Eq. (6) and taking values of $L, E$ and $I$ from Tables 1 and

2 , the stiffness provided by an equivalent shallow pad foundation in a full-scale case, $k_{f, N U M}$, is calculated to be $234 \times 10^{3} \mathrm{kN} \mathrm{m}^{-1}$. In order to check the validity of this assumption, a benchmark geotechnical case is considered. Using the approach in Fitzgerald et al. (2019b) and FEMA (2000), and taking appropriate values for sand shear modulus from Prendergast and Gavin (2016), the stiffness provided by a shallow pad foundation of length, $4 \mathrm{~m}$ and width, 2 $\mathrm{m}$ is $172 \times 10^{3} \mathrm{kN} \mathrm{m}^{-1}$ for a loose sand and $344 \times 10^{3} \mathrm{kN} \mathrm{m}^{-1}$ for a medium dense sand. The scaled experimental spring stiffness used in the present study lies within this range and can therefore be understood to represent a loose to medium dense uniform sand deposit. The mass

411 of each pier, $m_{\text {pier }}$, was $12.56 \mathrm{~kg}$, obtained from measuring the approximate volume of steel 412 directly above the four springs.

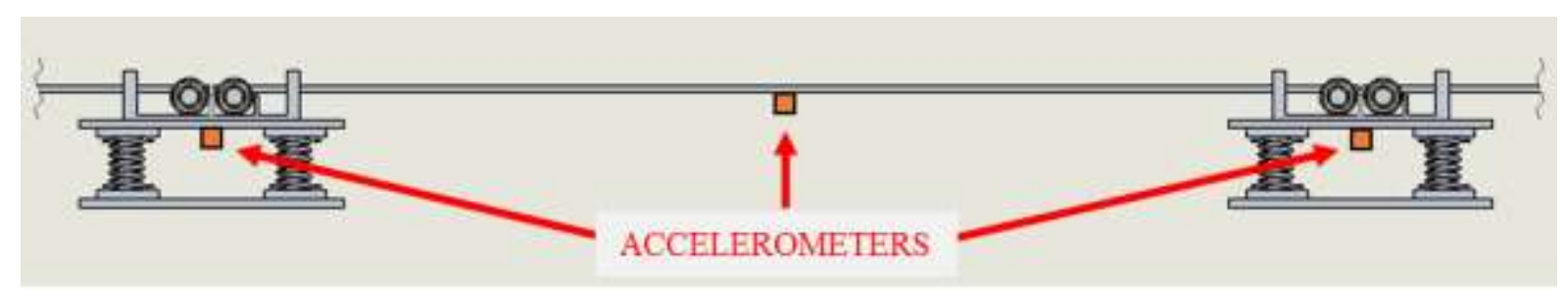




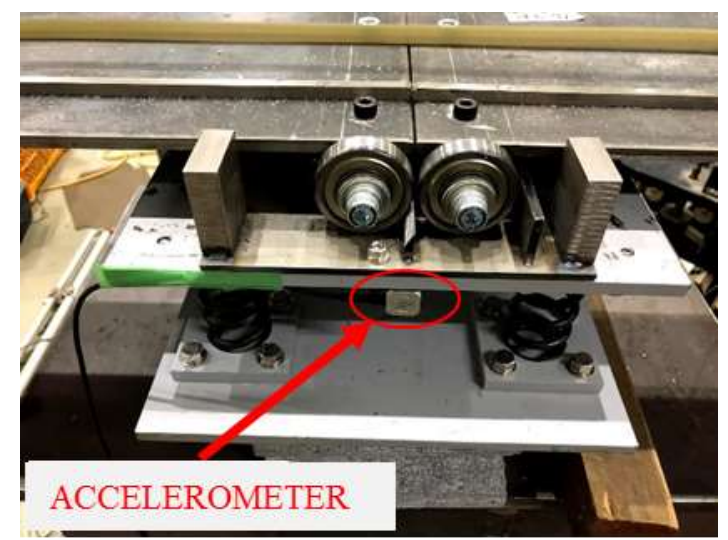

(b)

415 Fig. 9: Accelerometer locations (a) schematic of positions on midspan and pier (b) picture of one pier

416 Accelerometers were installed on each of the piers and at the midspans (Fig. 9). Seven bridge

417 acceleration measurements were recorded $(3 \times$ Piers and $4 \times$ Midspans). Optical sensors were

418 also installed at the beginning and end of the bridge, enabling the timing of when each vehicle

419 axle arrived and departed the bridge be obtained. To model the reduction in stiffness due to

420 scour at a pier, the springs under the pier (Figs. 8(b), 9(b)) were replaced with four springs of

421 a lower stiffness value for a given scour case. Two scour cases were considered, Case I where

422 parallel springs, each of stiffness $37 \mathrm{~N} \mathrm{~mm}^{-1}$, were used and Case II where parallel springs with

423 stiffness of $27 \mathrm{~N} \mathrm{~mm}^{-1}$ were used. These cases equated to $24.5 \%$ and $44.9 \%$ stiffness reductions

424 from the healthy case where each parallel spring had a stiffness of $49 \mathrm{~N} \mathrm{~mm}^{-1}$.

\section{Vehicle}

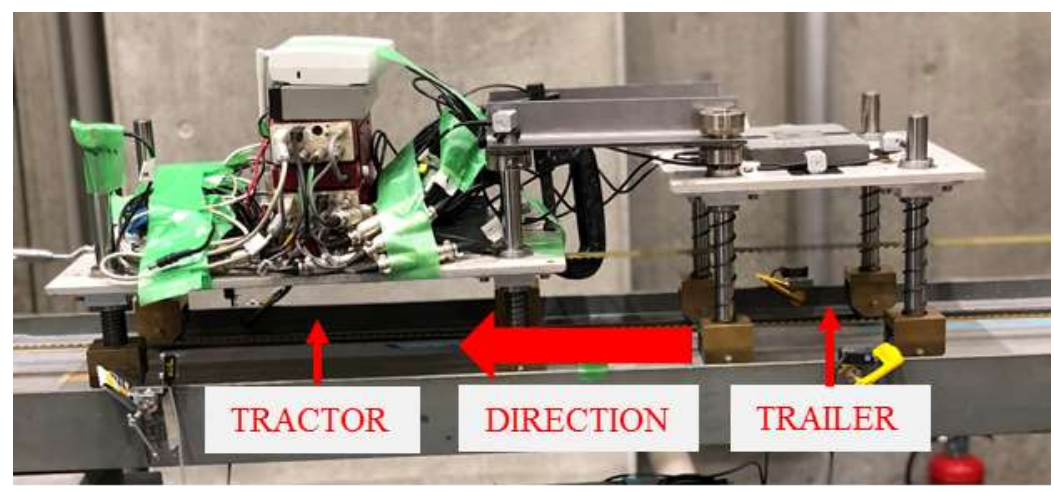

(a) 


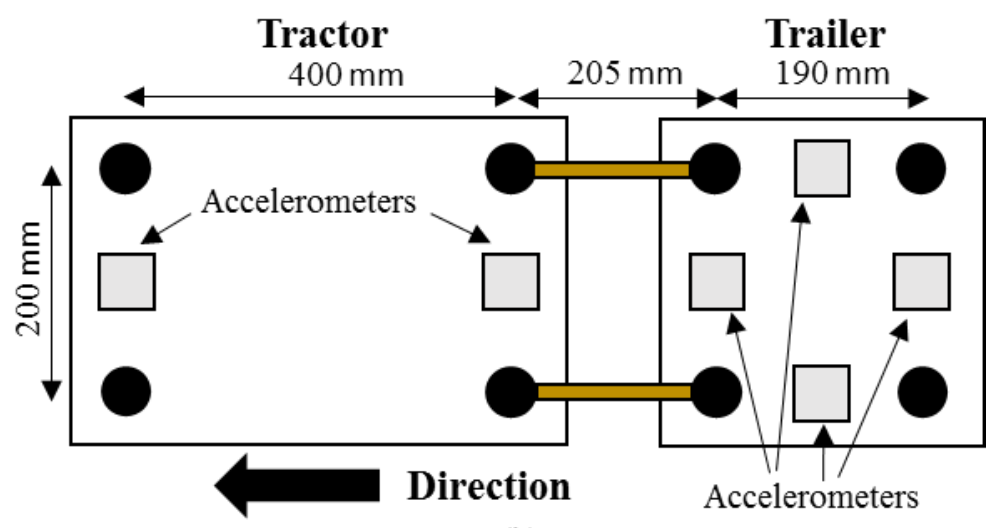

(b)

Fig. 10: (a) Experimental vehicle consisting of a tractor and trailer which are connected (b) Dimensions in plan view of the vehicle

The vehicle used in the experiments is shown in Fig. 10(a). It consisted of a two-axle tractor, connected to a two-axle trailer. Both the tractor and trailer consisted of sprung steel plates. The front tractor axle had two springs of stiffness $1533 \mathrm{~N} \mathrm{~m}^{-1}$ and the rear axle had two springs of stiffness $1753 \mathrm{~N} \mathrm{~m}^{-1}$. The trailer had four equal axle suspension springs of stiffness $8464 \mathrm{~N} \mathrm{~m}^{-}$ ${ }^{1}$. The tractor and trailer had axle spacings of $400 \mathrm{~mm}$ and $190 \mathrm{~mm}$ respectively and the spacing between the rear tractor axle and front trailer axle was $205 \mathrm{~mm}$ (Fig. 10(b)).

The vehicle speed was kept constant by an electronic controller as it traversed the bridge. Traversing speeds of $1.14 \mathrm{~m} / \mathrm{s}$ and $1.26 \mathrm{~m} / \mathrm{s}$ were used in this experiment. Two different tractor masses, $24.3 \mathrm{~kg}$ and $26.3 \mathrm{~kg}$ were investigated to study potential sensitivity issues. The sprung mass (i.e. the mass supported by springs) of the tractor for these two weights was $20.7 \mathrm{~kg}$ and $22.7 \mathrm{~kg}$ respectively. The trailer mass was $13.7 \mathrm{~kg}$ (of which $10.1 \mathrm{~kg}$ was sprung). The vehicle was maintained on the bridge by two steel tracks, see Fig. 11. Accelerometers were installed on the tractor and trailer in the locations shown in Fig. 10(b) which allows the vehicle frequencies to be calculated. The tractor had bounce and pitch frequencies of $3.1 \mathrm{~Hz}$ and 4.7 $\mathrm{Hz}$ respectively (for the $20.7 \mathrm{~kg}$ case) and the trailer had bounce and pitch frequencies of 6.6 $\mathrm{Hz}$ and $3.5 \mathrm{~Hz}$ respectively. These were obtained using free vibration vehicle acceleration measurements (after the vehicle has come to a halt) which were subsequently analysed using 
447 Frequency Domain Decomposition (FDD) (Brincker et al., 2001), enabling the pitch and 448 bounce modes be distinguished.

449

450

\section{Experimental Results}

452 The concept of using relative pier mode shape amplitudes is introduced in a previous section using theoretical mode shapes extracted from Eigen-analyses (Clough and Penzien, 1993) and a brief numerical demonstration. In this section, the procedure is applied to the acceleration signals generated at various points on a scaled bridge structure (see previous section) to ascertain how successful the approach is when the modal information is extracted directly from time signals incorporating natural experimental error.

\section{Procedure}

In the experimental tests, the model vehicle traversed the bridge at a specified velocity resulting in four acceleration measurements from the midspans and three from the piers. The resulting accelerations contain components relating to both the vehicle-induced vibrations and the subsequent free vibration. The time-domain signals are analysed using FDD to identify the mode shapes. Two vehicle speeds and tractor masses are investigated to ascertain how experimental variation influences the results. The FDD processing is undertaken in the MATLAB programming environment.

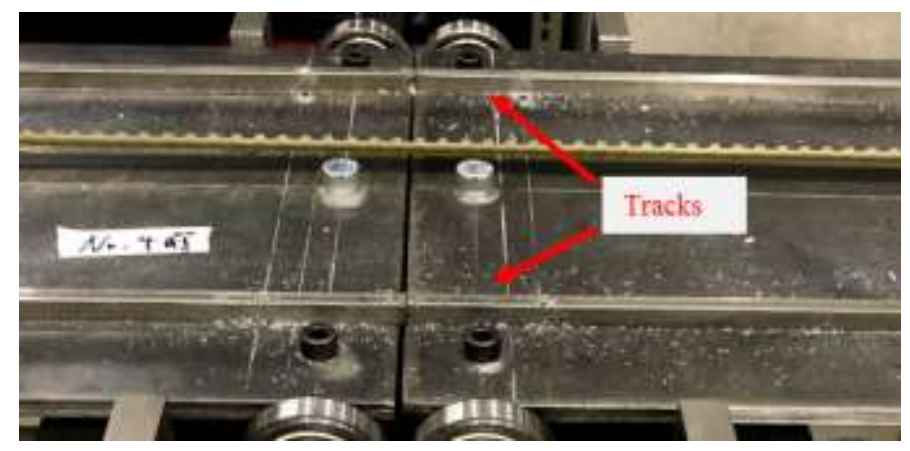

Fig. 11: Vehicle Tracks 


\section{Extraction of mode shapes for healthy case}

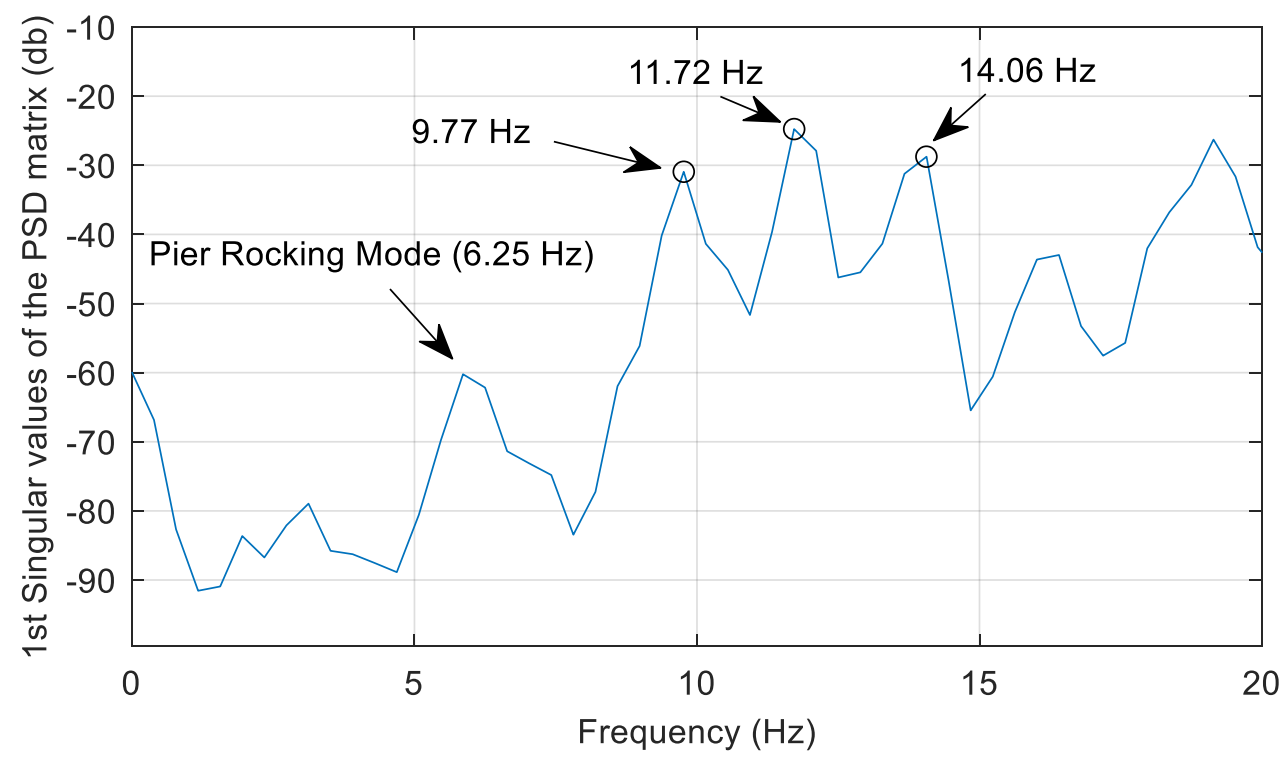

Fig. 12: Experimental FDD frequency picking from singular values of the spectral density matrix for vehicle crossing at speed of $1.26 \mathrm{~m} / \mathrm{s}$ (with tractor mass of $22.7 \mathrm{~kg}$ )

470 Fig. 12 shows the $1^{\text {st }}$ singular values of the Power Spectral Density (PSD) matrix obtained by

471 applying FDD to the seven acceleration signals resulting from the vehicle (with tractor mass 472 of $22.7 \mathrm{~kg}$ ) traversing the bridge at $1.26 \mathrm{~m} / \mathrm{s}$. As is evident, many peaks appear on the plot, 473 each corresponding to a different mode of vibration. To demonstrate the process of deriving 474 the mode shapes, three peaks are identified herein at $9.77 \mathrm{~Hz}, 11.72 \mathrm{~Hz}$ and $14.06 \mathrm{~Hz}$. There is 475 also a smaller peak visible at $6.25 \mathrm{~Hz}$, which correlates to a pier rocking mode. Fig. 13 shows 476 the extracted mode shapes corresponding to the three frequency peaks selected in Fig. 12. For 477 ease of visualisation, a spline curve is fitted to the extracted points. 


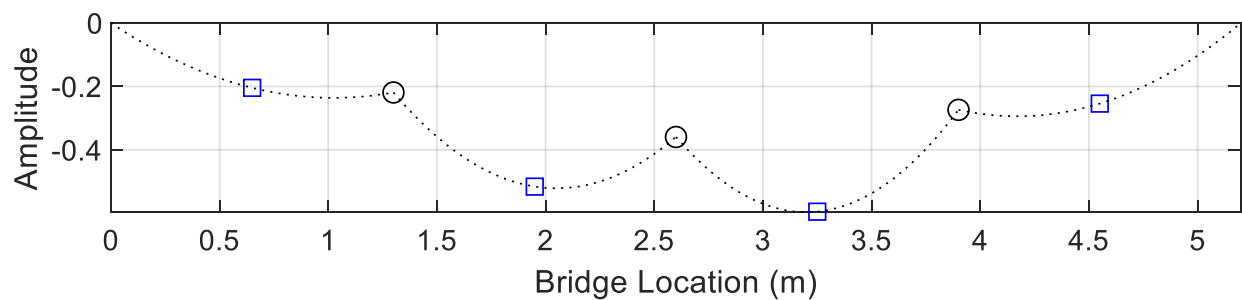

(a)

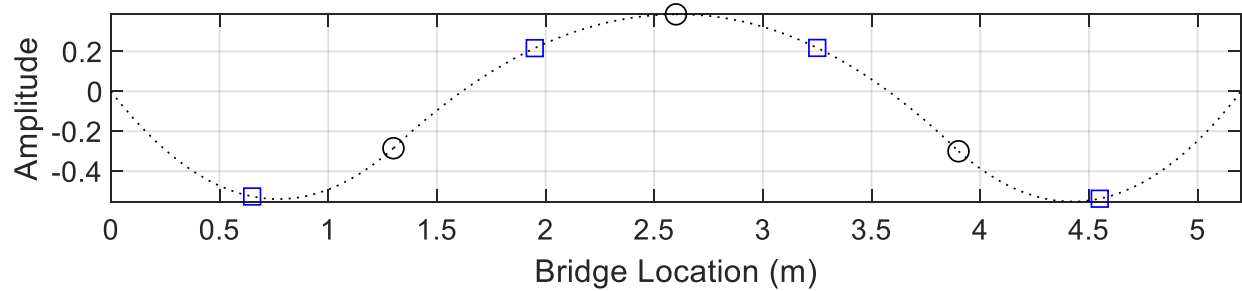

(b)

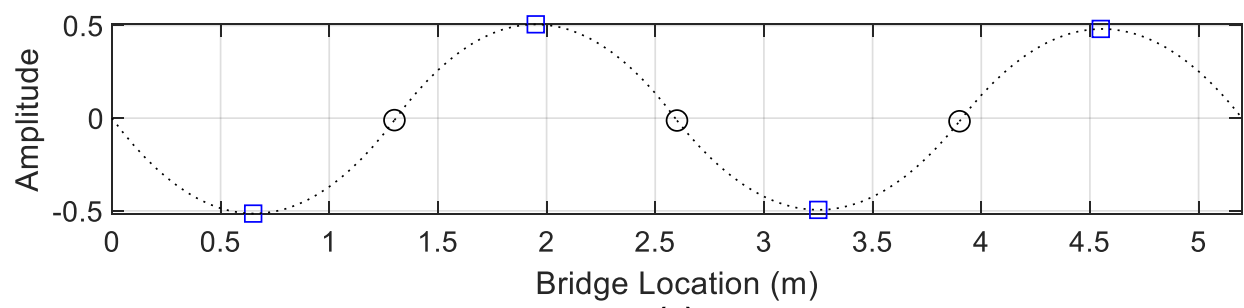

(c)

\begin{tabular}{|llll|}
\hline & Supports $\quad \square \quad$ Midspans $\cdots \cdots \cdots \cdots \cdots \cdot$. Fitted Spline \\
\hline
\end{tabular}

Fig. 13: Mode shapes derived from experimental accelerations - (a) $9.77 \mathrm{~Hz}$ mode, (b) $11.72 \mathrm{~Hz}$ mode, (c) 14.06 $\mathrm{Hz}$ mode

Fig. 13(a) shows the first mode of the structure, at a frequency of $9.77 \mathrm{~Hz}$. This mode shape resembles that of the numerical model of the full-scale structure shown in Fig. 2 in that all the piers are moving in the same direction. This is the 'first' mode shape and is the primary focus of the present work to detect a loss of stiffness due to scour. The $11.72 \mathrm{~Hz}$ mode (Fig. 13(b)) differs from the $9.77 \mathrm{~Hz}$ mode in that Pier 2 (the centre pier) is moving in a different direction to Piers 1 and 3. Finally, in the $14.06 \mathrm{~Hz}$ mode (Fig. 13(c)), the piers exhibit negligible movement in comparison to the midspans. Due to this, the $9.77 \mathrm{~Hz}$ and $11.72 \mathrm{~Hz}$ modes would have an expected change due to scour but the $14.06 \mathrm{~Hz}$ mode would not (as the piers have insignificant modal amplitudes in this mode). 


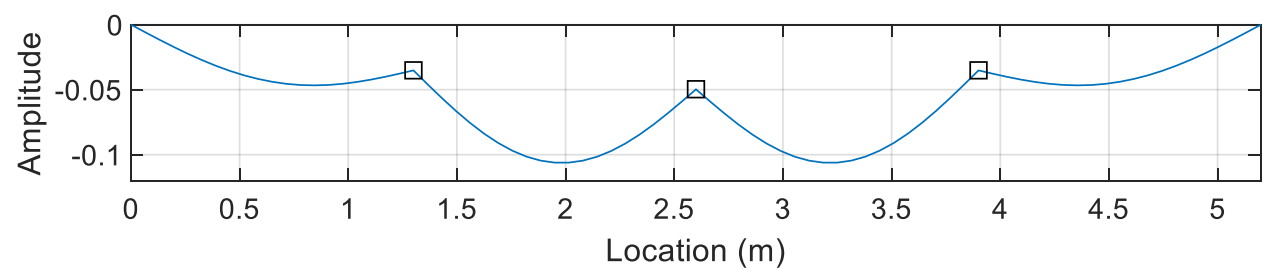

(a)

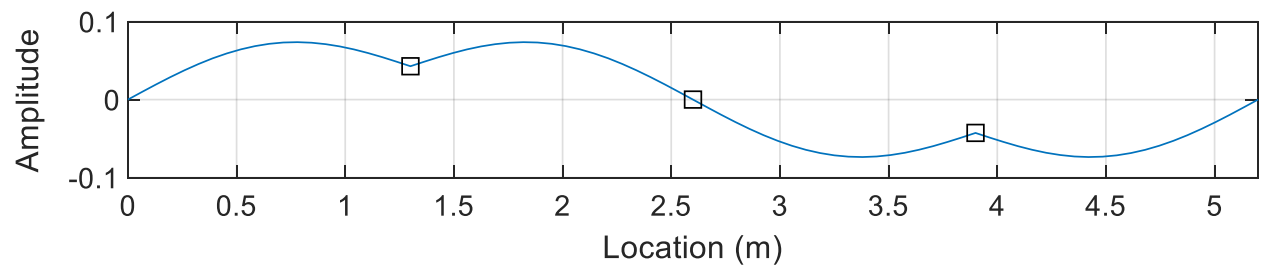

(b)

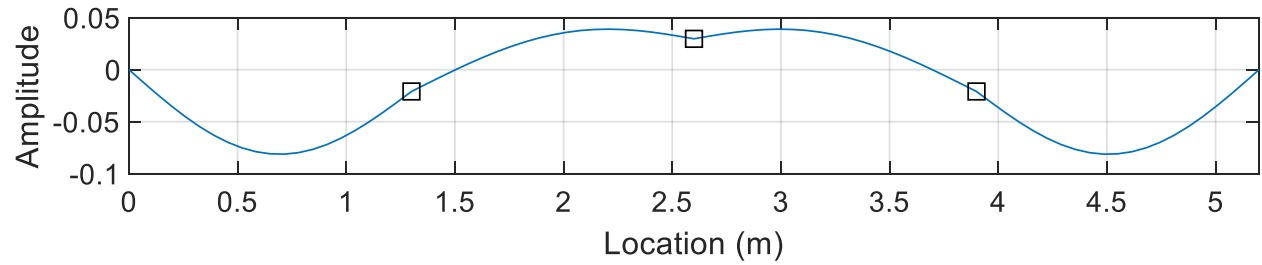

(c)

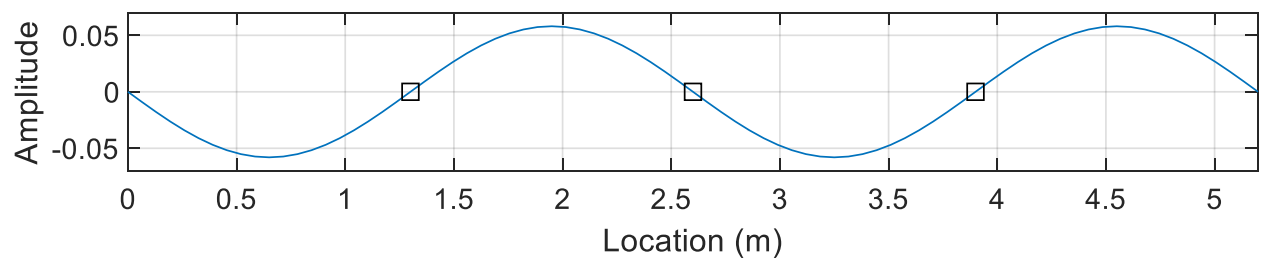

(d)

490

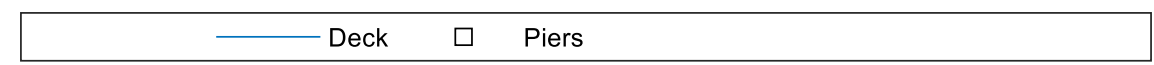

491 492

493 A numerical model of the scaled experimental arrangement is developed using the approach 494

495

496

497

498

499

Fig. 14: First four mode shapes of system from numerical model - (a) $9.66 \mathrm{~Hz}$ mode, (b) $10.55 \mathrm{~Hz}$ mode, (c) 12.09 $\mathrm{Hz}$ mode, (d) $13.85 \mathrm{~Hz}$ mode described previously and using the experimental parameters in Table 2. Fig. 14 shows the mode shapes of the first four frequencies derived from the numerical model by solving the Eigenproblem of the system matrices (Clough and Penzien, 1993). It is worth noting that the pier stiffness, $k_{p i e r}$, in the model is assumed to be infinite compared to the foundation stiffness, $k_{f}$. Here, the value of $k_{\text {pier }}$ is selected by multiplying $k_{f}$ by $10^{4}$ (i.e. an arbitrary large number). The steel tracks are also included in the numerical model so the beam second moment of area and cross-sectional area are altered to account for this. With the tracks included, these properties are $21.67 \times 10^{3} \mathrm{~mm}^{4}$ and $2549 \mathrm{~mm}^{2}$ respectively. 
502 A comparison of the experimental mode shapes (Fig. 13) derived from the time-domain

503 acceleration signals and the numerically calculated ones (with the experimental model

504 parameters - Fig. 14) shows clear similarities. The experimental and numerical modes of 9.77

$505 \mathrm{~Hz}$ and $9.66 \mathrm{~Hz}$ (Figs. 13(a) and 14(a)), $11.72 \mathrm{~Hz}$ and $12.09 \mathrm{~Hz}$ (Figs. 13(b) and 14(c)) and

$506 \quad 14.06 \mathrm{~Hz}$ and $13.85 \mathrm{~Hz}$ (Figs. 13(c) and 14(d)) show a clear correspondence, which provides a

507 reasonable level of confidence in the experimental results from the FDD algorithm. Given the

508 difficulties associated with accurately modelling the real experimental situation, the differences

509 in the frequencies between numerical and experimental cases are relatively minor. The

510 numerical mode of $10.55 \mathrm{~Hz}$ (Fig. 14(b)) is not sufficiently excited by the traversing model

511 vehicle in the experiment to show in the peak selection process in Fig. 12. Of note is the

512 frequency for the numerical mode in Fig. 14(d). The frequency of $13.85 \mathrm{~Hz}$ is the same as the

513 first natural frequency of a single span simply supported beam case. This is unsurprising as the

514 piers do not show any deflection in Fig. 14(d), equivalent to pinned supports. 


\section{Extraction of mode shapes for scoured case}

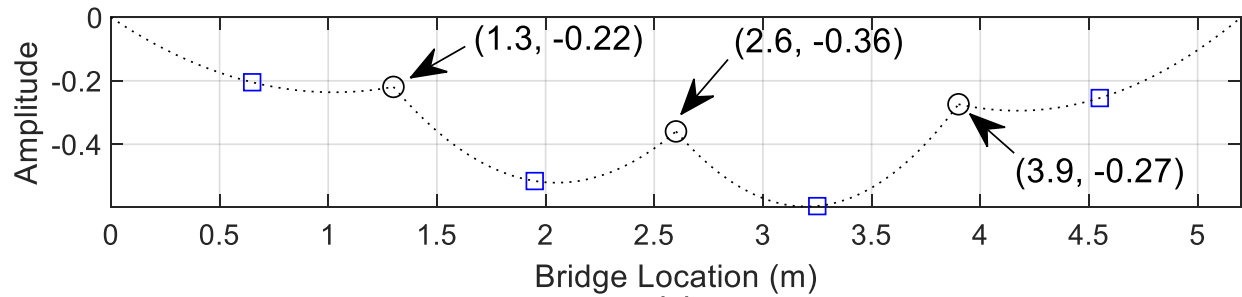

(a)

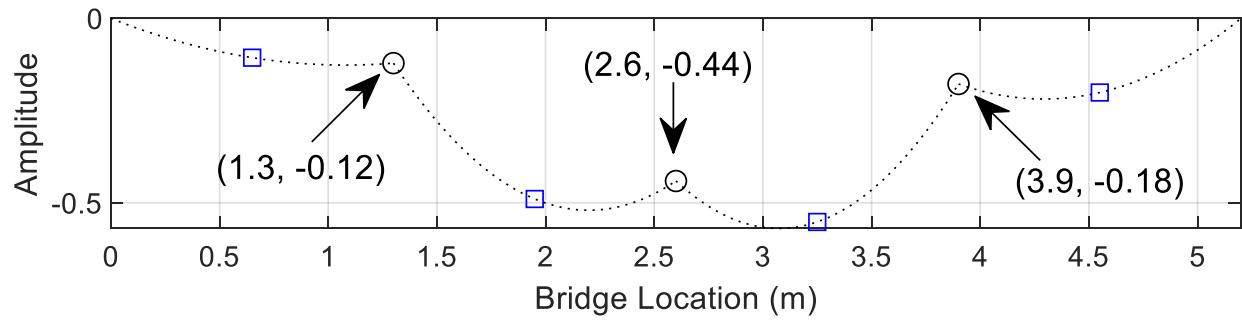

(b)

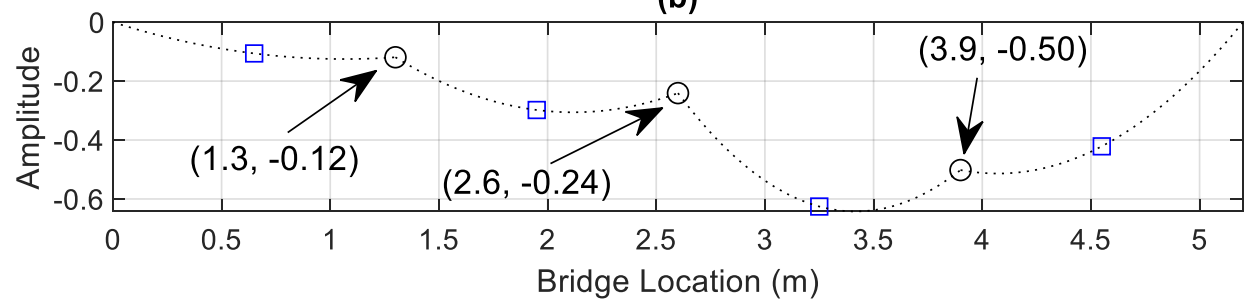

(c)

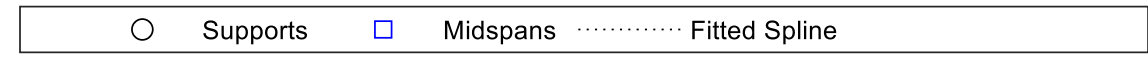

517

518

519

520

521

522

523

524

525

526

527

528
Fig. 15: First mode shape (derived from experimental accelerations) for different scour scenarios for vehicle crossing at speed of $1.26 \mathrm{~m} / \mathrm{s}$ (with a tractor mass of $22.7 \mathrm{~kg}$ ) - (a) Healthy case, (b) $24.5 \%$ stiffness loss at Pier 2, (c) $24.5 \%$ stiffness loss at Pier 3

Fig. 15 shows how the first mode shape of the experimental bridge changes for the scour scenarios equivalent to $24.5 \%$ stiffness loss at Pier 2 (with other piers remaining healthy) and $24.5 \%$ foundation stiffness loss at Pier 3 (with the other piers remaining healthy). For each case, the change in mode shape amplitude is greatest at the location of the scoured pier. Table 3 shows the MNMS values which are defined in Eq. (2) for the scenarios in Fig. 15. The MNMS value at the scoured pier increases due to scour stiffness loss while the MNMS values at the other piers decrease. This generally corroborates the findings from the numerical study in a previous section. Moreover, the percentage increases in the MNMS values are greater for the case of scour at Pier 3 than at Pier 2 - 0.93 to 2.78 (198.9\% increase) vs 1.47 to 2.93 (99.3\% 
529 increase). This is in line with the findings from the numerical study in that the MNMS value

530 increases more for stiffness loss at an off-centre pier than at the central pier.

531 Table 3: Experimental MNMS values calculated for 24.5\% stiffness reduction (using values marked in Fig. 15)

532

\begin{tabular}{|l|c|c|c|}
\hline Scour Condition & MNMSPier 1 & MNMSPier 2 & MNMSPier 3 \\
\hline Healthy & 0.70 & 1.47 & 0.93 \\
\hline $24.5 \%$ Scour Pier 2 & 0.39 & 2.93 & 0.64 \\
\hline $24.5 \%$ Scour Pier 3 & 0.32 & 0.77 & 2.78 \\
\hline
\end{tabular}

533 Sensitivity of MNMS for different locations and severities of scour

534 considering vehicle condition variability

535 Fig. 16 shows the MNMS values for scour at Pier 2 calculated from different vehicle runs for

536 a healthy case and stiffness losses due to scour of $24.5 \%$ and $44.9 \%$. Two different tractor

537 masses and vehicle speeds are investigated with each repeated three times for each scenario.

538 The tractor masses tested are $24.3 \mathrm{~kg}$ and $26.3 \mathrm{~kg}$, and the vehicle speeds are $1.14 \mathrm{~m} \mathrm{~s}^{-1}$ and

$5391.26 \mathrm{~m} \mathrm{~s}^{-1}$. The MNMS values in Fig. 16 are shown relative to each vehicle run and the specific

540 conditions are shown below Fig. 16(c). The MNMS values are quite repeatable for each scour

541 case. This is not unexpected, as the indicators are based on a vibration mode of the structure,

542 so they should not be significantly affected by a change in vehicle parameters. The results for

543 the case considered (scour at Pier 2) show that the MNMS increases in value at the scoured

544 pier for the two scour magnitudes considered and decreases at the remaining piers (relative to

545 the healthy case). 


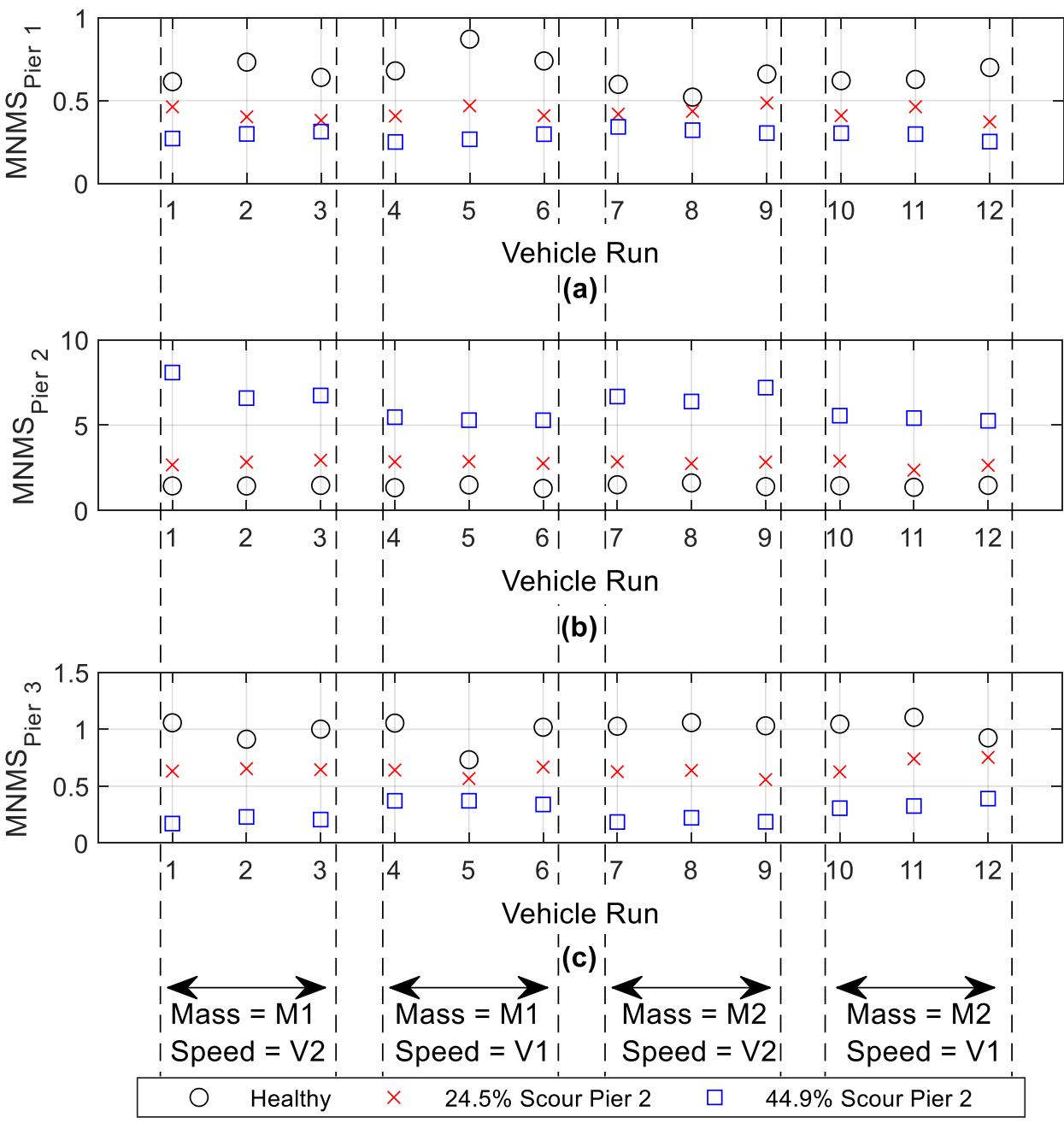

Fig. 16: MNMS values for scour at Pier 2 repeated for multiple vehicle runs where M1 and M2 refer to tractor masses of $24.3 \mathrm{~kg}$ and $26.3 \mathrm{~kg}$ respectively and $\mathrm{V} 1$ and $\mathrm{V} 2$ refer to vehicle speeds of $1.14 \mathrm{~m} / \mathrm{s}$ and $1.26 \mathrm{~m} / \mathrm{s}$ respectively (a) $\mathrm{MNMS}_{\text {Pier1 }}$ (b) $\mathrm{MNMS}_{\text {Pier2 }}$ (c) $\mathrm{MNMS}_{\text {Pier3 }}$

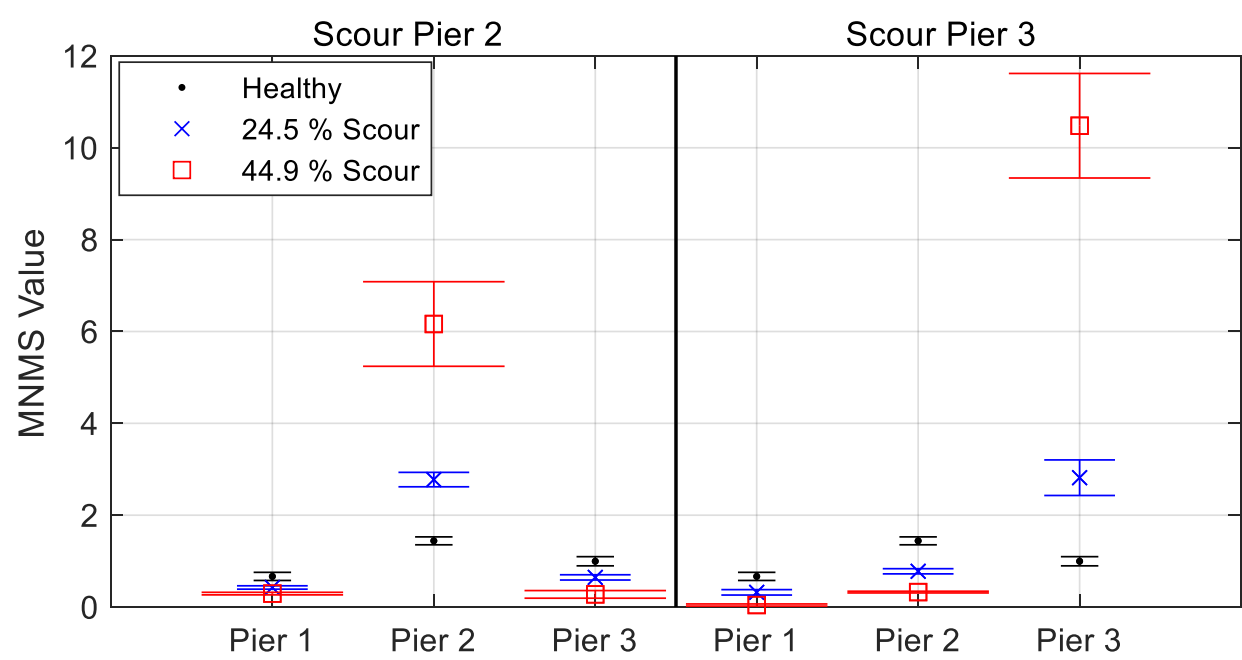

Fig. 17: Mean and one standard deviation error bar plots of scour scenarios at Pier 2 and Pier 3 for severities of 
553 Fig. 17 (left side) shows the mean of the MNMS values for the 12 runs considered in Fig. 16

554 +/- one standard deviation (shown by error bars on the plot). The same information is shown

555 on the right side of the plot for the case where the scour is at Pier 3. There is a clear distinction

556 between the regions defined by the error bars for each scour scenario. In other words, the error

557 bars do not overlap, which shows that the effect of scour outweighs any variability effects

558 (within 1 standard deviation) due to the vehicle changes considered or natural variability due

559 to measurement error. It can also be seen in Fig. 17 that the scale of the increases at the scoured

560 pier are far greater than the changes at the unscoured piers, making it clear which pier is scoured

561 for a given case. Similar to the findings in the numerical study, the MNMS experiences a

562 greater increase for off-centre piers than for central piers. This is shown in Fig. 17 for the $44.9 \%$

563 scour case where there is a larger change in MNMS at Pier 3 for the case of scour at Pier 3 than

564 the change in the MNMS at Pier 2 for the case of scour at Pier 2.

\section{Performance of MNMS against Modal Assurance Criterion (MAC)}

566 The performance of the MNMS approach against traditional damage-detection methods based

567 on comparing healthy and damaged mode shapes using MAC is of interest. In this section, a

568 brief analysis is conducted to assess the relative performance of MNMS and MAC as indicators

569 of scour damage. The experimental results from vehicles crossing the model bridge are used to

570 derive the mode shapes for the case of the healthy bridge, and the bridge 'damaged' by scour

571 with stiffness reductions of $24.5 \%$ and $44.9 \%$ at Pier 2 . In total, six crossing of the healthy

572 case, and six crossings for each of the two damage cases are used to obtain the mean values of

573 the mode shapes for each condition. MAC is defined as in Eq. (7)

$$
\text { MAC }=\frac{\left|\Phi_{\text {healthy }}{ }^{\mathrm{t}} \Phi_{\text {damaged }}\right|^{2}}{\left|\Phi_{\text {healthy }}{ }^{\mathrm{t}} \Phi_{\text {healthy }}\right|\left|\Phi_{\text {damaged }}{ }^{\mathrm{t}} \Phi_{\text {damaged }}\right|}
$$


where $\Phi_{\text {healthy }}$ is the mode shape obtained from the healthy bridge, $\Phi_{\text {damaged }}$ is the mode

575 shape obtained from the scoured bridge and " $\mathrm{t}$ " defines the matrix transpose. If the mode shapes

576 are identical, the MAC will have a value of one, but if they are very different, the MAC value

577 will be close to zero.

578 Table 4 shows the results of the MAC analysis. A MAC value of 0.9 between healthy and 579 damaged mode shapes is obtained for the case of $24.5 \%$ scour-related stiffness loss at Pier 2.

580 This reduces to 0.71 for an increased stiffness reduction to $44.9 \%$ at Pier 2 . Table 5 shows the

581 MNMS derived for the same conditions. For $24.5 \%$ scour at P2, MNMS at P2 increases by

582 almost $100 \%$, and decreases by $41 \%$ and $34 \%$ at P1 and P3 respectively. For $44.9 \%$ scour at P2, MNMS at P2 increases by almost $341 \%$, and decreases by $61 \%$ and $71 \%$ at P1 and P3 respectively relative to the zero scour case. From this analysis, it can be seen that MNMS is more sensitive to scour damage than MAC, and moreover the location of scour can be detected by observing the relative changes in the MNMS value at each pier. MNMS is potentially a better indicator than the traditional MAC value for scour type damage detection.

Table 4 MAC Analysis

\begin{tabular}{|l|l|l|l|l|}
\hline & \multicolumn{3}{|c|}{ Modal Amplitudes (-) } & \\
\hline Case & Pier 1 & Pier 2 & Pier 3 & MAC \\
\hline Healthy & -0.23 & -0.36 & -0.28 & - \\
\hline $24.5 \%$ Scour & -0.14 & -0.45 & -0.19 & 0.9 \\
\hline $44.9 \%$ Scour & -0.10 & -0.62 & -0.10 & 0.71 \\
\hline
\end{tabular}

\begin{tabular}{|l|l|l|l|l|l|l|}
\hline Case & MNMSP1 & \% Change & MNMSP2 & \% Change & MNMSP3 & \% Change \\
\hline Healthy & 0.71 & - & 1.41 & - & 0.96 & - \\
\hline $\begin{array}{l}24.5 \% \\
\text { Scour }\end{array}$ & 0.42 & -41 & 2.82 & 100 & 0.63 & -34 \\
\hline $\begin{array}{l}44.9 \% \\
\text { Scour }\end{array}$ & 0.28 & -60 & 6.24 & 341 & 0.28 & -71 \\
\hline
\end{tabular}




\section{Conclusions}

593 This paper presents an approach to detect stiffness loss arising due to scour based on relative

594 changes of vertical pier mode shape amplitudes. The method is tested using a scaled

595 experimental model of a bridge traversed by a vehicle. The experimental mode shapes are extracted from acceleration signals arising due to the vehicle crossing using an output only modal identification technique, namely Frequency Domain Decomposition. A scour monitoring feature (MNMS) is defined, based on the first global mode shape of the structure and is shown to increase significantly at a scoured pier. At the location of the scoured pier the magnitude of the MNMS also increases with scour severity, suggesting that progressive scour development could potentially be monitored. As the algorithm used is an output-only one, it has the advantage of negating the requirement of knowing any details about the vehicle excitation forces. Furthermore, material and geometrical information about the bridge such as second moment of area or density, do not need to be known in order to apply the method. Repeated vehicle runs to excite the bridge allow the MNMS to be derived and monitoring changes in this metric alone can potentially detect scour. In practice, an initial visual inspection of the bridge may help to determine the scour condition at the time of instrumentation, and this would be the benchmarked 'unscoured' case. Once instrumented, the bridge can potentially be monitored on a continual basis using the method proposed in this paper.

610 It should be noted that while scour is the target damage in the present study, other forms of

611 damage such as concrete spalling or corrosion will also lead to changes in stiffness of a

612 structure. Separating the scour influence from other damage types is challenging, however by 613 the very nature of scour occurring at supports, the relative changes in stiffness due to scour are 614 expected to be larger than would arise under other damage types. Additionally, if the MNMS 615 were to detect some form of stiffness loss (from scour or otherwise), this could be used to 616 trigger a manual visual inspection. It is therefore not so important to separate scour from other 
617 damage as the end result for a bridge manager is to detect any issues arising in the structure to

618 facilitate the safe management of the asset.

619 The analysis in this paper considers scour at only one pier at a time to demonstrate the approach.

620 Scour at multiple piers simultaneously can cause issues with the method as it is derived using

621 the sum of the modal amplitudes at all piers to identify scour at a given affected pier. The 622 method therefore does not work well when scour affects multiple piers of a bridge 623 simultaneously. However, due to asymmetry in water-flow characteristics across a river 624 channel cross-section, it is unlikely for temporal scour development to be equal at multiple 625 piers, therefore the approach should still be capable of identifying scour occurrence once it 626 begins at a given pier.

627 While the approach was successfully demonstrated with an experimental scaled bridge in the

628 present study, a full-scale deployment is recommended before firm conclusions on the efficacy 629 of the method can be made. This is due to the natural differences that arise between $1 g$ scaled 630 experimental testing and full-scale applications.

631 The approach described in this paper is novel in terms of bridge scour detection and will be 632 beneficial to the evolving vibration-based scour monitoring field.

\section{Data Availability Statement}

634 Some or all data, models, or code that support the findings of this study are available from the 635 corresponding author upon reasonable request. (Experimental Data.)

\section{Acknowledgements}

637 The authors wish to acknowledge the financial support received from Science Foundation 638 Ireland under the US-Ireland Research Partnership Scheme, Grant No. 14/US/I3033. 
639

640

641

642

643

644

645

646

647

648

649

650

651

652

653

654

655

656

657

658

659

660

661

\section{References}

Allemang, R. J. \& D. L. Brown. 1982. "A correlation coefficient for modal vector analysis". Proceedings of the 1st International Modal Analysis Conference, 110-116.

Bao, T. \& Z. Liu. 2017. "Vibration-based bridge scour detection: A review". Structural Control and Health Monitoring, 24(7), e1937.

Bao, T., R. A. Swartz, S. Vitton, Y. Sun, C. Zhang \& Z. Liu. 2017. "Critical insights for advanced bridge scour detection using the natural frequency". Journal of Sound and Vibration, 386, 116-133.

Briaud, J. L., S. Hurlebaus, K. A. Chang, C. Yao, H. Sharma, O. Y. Yu, C. Darby, B. E. Hunt \& G. R. Price, 2011. Realtime monitoring of bridge scour using remote monitoring technology, Texas A\&M University System, Texas.

Briaud, J. L., Z. Medina-Cetina, S. Hurlebaus, M. Everett, S. Tucker, N. Yousefpour \& R. Arjwech, 2012. Unknown foundation determination for scour, Texas Transportation Institute, Texas.

Brincker, R., L. Zhang \& P. Andersen. 2001. "Modal identification of output-only systems using frequency domain decomposition". Smart Materials and Structures, 10(3), 441445.

Carden, E. P. \& P. Fanning. 2004. "Vibration based condition monitoring: a review". Structural Health Monitoring, 3(4), 355-377.

Chen, C. C., W. H. Wu, F. Shih \& S. W. Wang. 2014. "Scour evaluation for foundation of a cable-stayed bridge based on ambient vibration measurements of superstructure". NDT \& E International, 66, 16-27.

Clough, R. W. \& J. Penzien 1993. Dynamics of Structures, McGraw-Hill. 
662 Davis, N. T., E. Hoomaan, M. Sanayei, A. K. Agrawal \& F. Jalinoos. 2018. "Integrated

663

664

665

666

667

668

669

670

671

672

673

674

675

676

677

678

679

680

681

682

683

684

685

686 Superstructure-Substructure Load Rating for Bridges with Foundation Movements". Journal of Bridge Engineering, 23(5), 04018022.

Dos Santos, J. A., C. M. Soares, C. M. Soares \& H. Pina. 2000. "A damage identification numerical model based on the sensitivity of orthogonality conditions and least squares techniques". Computers \& Structures, 78(1-3), 283-291.

Elsaid, A. \& R. Seracino. 2014. "Rapid assessment of foundation scour using the dynamic features of bridge superstructure". Construction and Building Materials, 50, 42-49.

Fan, W. \& P. Qiao. 2011. "Vibration-based damage identification methods: a review and comparative study". Structural Health Monitoring, 10(1), 83-111.

FEMA, 2000. Prestandard and commentary for the seismic rehabilitation of buildings Report FEMA-356, Washington, DC.

Fitzgerald, P. C., A. Malekjafarian, B. Bhowmik, L. J. Prendergast, P. Cahill, C. W. Kim, B. Hazra, V. Pakrashi \& E. J. OBrien. 2019a. "Scour Damage Detection and Structural Health Monitoring of a Laboratory-Scaled Bridge Using a Vibration Energy Harvesting Device". Sensors, 19(11), 2572.

Fitzgerald, P. C., A. Malekjafarian, D. Cantero, E. J. OBrien \& L. J. Prendergast. 2019b. "Drive-by scour monitoring of railway bridges using a wavelet-based approach". Engineering Structures, 191, 1-11.

Forde, M., D. Mccann, M. Clark, K. Broughton, P. Fenning \& A. Brown. 1999. "Radar measurement of bridge scour". NDT \& E International, 32(8), 481-492.

Foti, S. \& D. Sabia. 2010. "Influence of foundation scour on the dynamic response of an existing bridge". Journal of Bridge Engineering, 16(2), 295-304.

Frýba, L. \& M. Pirner. 2001. "Load tests and modal analysis of bridges". Engineering Structures, 23(1), 102-109. 
687 Hamill, L. 1999. Bridge Hydraulics, Routledge, London \& New York, E.\& F.N. Spon.

688 Hardin, B. O. \& V. P. Drnevich. 1972. "Shear Modulus and Damping in Soils: Design Equations and Curves". Journal of the Soil Mechanics and Foundations Division, 98(7), 667-692.

Ju, S. 2013. "Determination of scoured bridge natural frequencies with soil-structure interaction". Soil Dynamics and Earthquake Engineering, 55, 247-254.

Keenahan, J., E. J. OBrien, P. J. Mcgetrick \& A. Gonzalez. 2013. "The use of a dynamic 694 truck-trailer drive-by system to monitor bridge damping". Structural Health

Khatibi, M., M. Ashory, A. Malekjafarian \& R. Brincker. 2012. "Mass-stiffness change method for scaling of operational mode shapes". Mechanical Systems and Signal Processing, 26, 34-59.

699

Klinga, J. V. \& A. Alipour. 2015. "Assessment of structural integrity of bridges under extreme scour conditions". Engineering Structures, 82, 55-71.

Kong, X. \& C. S. Cai. 2016. "Scour Effect on Bridge and Vehicle Responses under BridgeVehicle-Wave Interaction". Journal of Bridge Engineering, 21(4), Article ID 04015083.

704

Kong, X., C. S. Cai \& S. Hou. 2013. "Scour effect on a single pile and development of

Kong, X., C. S. Cai \& J. Hu. 2017. "The state-of-the-art on framework of vibration-based structural damage identification for decision making". Applied Sciences, 7(5), 497. Florida, CRC press. 
711 Maddison, B. 2012. "Scour failure of bridges". Proceedings of the Institution of Civil Engineers-Forensic Engineering, 165(1), 39-52.

713

Malekjafarian, A. \& E. J. OBrien. 2014. "Identification of bridge mode shapes using short time frequency domain decomposition of the responses measured in a passing vehicle". Engineering Structures, 81, 386-397.

Malekjafarian, A. \& E. J. OBrien. 2017. "On the use of a passing vehicle for the estimation of bridge mode shapes". Journal of Sound and Vibration, 397, 77-91.

Moughty, J. J. \& J. R. Casas. 2017. "A state of the art review of modal-based damage detection in bridges: Development, challenges, and solutions". Applied Sciences, 7(5), 510.

Mylonakis, G., S. Nikolaou \& G. Gazetas. 2006. "Footings under seismic loading: Analysis and design issues with emphasis on bridge foundations". Soil Dynamics and Earthquake Engineering, 26(9), 824-853.

OBrien, E. J., P. C. Fitzgerald, A. Malekjafarian \& E. Sevillano. 2017. "Bridge damage detection using vehicle axle-force information". Engineering Structures, 153(Supplement C), 71-80.

OBrien, E. J. \& A. Malekjafarian. 2016. "A mode shape-based damage detection approach using laser measurement from a vehicle crossing a simply supported bridge". Structural Control and Health Monitoring, 23(10), 1273-1286.

Oztoprak, S. \& M. Bolton. 2013. "Stiffness of sands through a laboratory test database". Géotechnique, 63(1), 54-70.

Pais, A. \& E. Kausel. 1988. "Approximate formulas for dynamic stiffnesses of rigid foundations". Soil Dynamics and Earthquake Engineering, 7(4), 213-227.

Pandey, A., M. Biswas \& M. Samman. 1991. "Damage detection from changes in curvature mode shapes". Journal of Sound and Vibration, 145(2), 321-332. 
736 Prendergast, L. J. \& K. Gavin. 2014. "A review of bridge scour monitoring techniques". Journal of Rock Mechanics and Geotechnical Engineering, 6(2), 138-149.

738

739

740

741

742

743

744

745

746

747

748

749

750

751

752

753

754

755

756

757

758

759

Prendergast, L. J. \& K. Gavin. 2016. "A comparison of initial stiffness formulations for small-strain soil-pile dynamic Winkler modelling". Soil Dynamics and Earthquake Engineering, 81, 27-41.

Prendergast, L. J., K. Gavin \& D. Hester. 2017. "Isolating the location of scour-induced stiffness loss in bridges using local modal behaviour". Journal of Civil Structural Health Monitoring, 7(4), 483-503.

Prendergast, L. J., D. Hester \& K. Gavin. 2016a. "Determining the presence of scour around bridge foundations using vehicle-induced vibrations". Journal of Bridge Engineering, 21(10), Article ID 04016065.

Prendergast, L. J., D. Hester \& K. Gavin, 2016b. Development of a vehicle-bridge-soil dynamic interaction model for scour damage modelling. Shock and Vibration. DOI: $10.1155 / 2016 / 7871089$

Prendergast, L. J., D. Hester, K. Gavin \& J. O’Sullivan. 2013. "An investigation of the changes in the natural frequency of a pile affected by scour". Journal of Sound and Vibration, 332(25), 6685-6702.

Prendergast, L. J., M. P. Limongelli, N. Ademovic, A. Anzlin, K. Gavin \& M. A. Zanini. 2018. "Structural Health Monitoring for Performance Assessment of Bridges under Flooding and Seismic Actions". Structural Engineering International, 28(3), 296-307.

Ratcliffe, C. P. 2000. "A frequency and curvature based experimental method for locating damage in structures". Journal of Vibration and Acoustics, 122(3), 324-329.

Salawu, O. S. \& C. Williams. 1995. "Bridge assessment using forced-vibration testing". Journal of Structural Engineering, 121(2), 161-173. 
760 Scozzese, F., L. Ragni, E. Tubaldi \& F. Gara. 2019. "Modal properties variation and collapse

761

762

763

764

765

766

767

768

769

770

771

772

773

774

775

776

777

778

779

780

781

782 assessment of masonry arch bridges under scour action". Engineering Structures, 199, 109665.

Sohn, H. 2006. "Effects of environmental and operational variability on structural health monitoring". Philosophical Transactions of the Royal Society A: Mathematical, Physical and Engineering Sciences, 365(1851), 539-560.

Sohn, H., C. R. Farrar, F. M. Hemez, D. D. Shunk, D. W. Stinemates, B. R. Nadler \& J. J. Czarnecki. 2003. "A review of structural health monitoring literature: 1996-2001". Los Alamos National Laboratory, USA.

Wahab, M. A. \& G. De Roeck. 1999. "Damage detection in bridges using modal curvatures: application to a real damage scenario". Journal of Sound and Vibration, 226(2), $217-$ 235.

Wardhana, K. \& F. C. Hadipriono. 2003. "Analysis of recent bridge failures in the United States". Journal of Performance of Constructed Facilities, 17(3), 144-150.

Xiong, W., C. Cai, B. Kong, P. Tang \& J. Ye. 2018a. "Identification of bridge scour depth by tracing dynamic behaviors of superstructures". KSCE Journal of Civil Engineering, 22(4), 1316-1327.

Xiong, W., C. Cai, B. Kong, X. Zhang \& P. Tang. 2019. "Bridge Scour Identification and Field Application Based on Ambient Vibration Measurements of Superstructures". Journal of Marine Science and Engineering, 7(5), 121.

Xiong, W., B. Kong, P. Tang \& J. Ye. 2018b. "Vibration-Based Identification for the Presence of Scouring of Cable-Stayed Bridges". Journal of Aerospace Engineering, 31(2), 04018007. 
783 Zhang, H., S. Chen \& F. Liang. 2017. "Effects of scour-hole dimensions and soil stress history on the behavior of laterally loaded piles in soft clay under scour conditions".

785 Computers and Geotechnics, 84, 198-209.

786 Zhu, X. Q. \& S. S. Law. 2002. "Moving loads identification through regularization". Journal of Engineering Mechanics, 128(9), 989-1000. 